\title{
Inaccuracies in Initial Growth and Arborization of Chick Retinotectal Axons Followed by Course Corrections and Axon Remodeling to Develop Topographic Order
}

\author{
Harukazu Nakamuraa and Dennis D. M. O'Leary \\ Departments of Anatomy and Neurobiology and of Neurology and Neurological Surgery, and The McDonnell Center for \\ Studies of Higher Brain Function, Washington University School of Medicine, St. Louis, Missouri 63110
}

The retinotectal projection is organized in a precise retinotopic manner. We find, though, that during development the growth and arborization of temporal retinal axons within the optic tectum of chick embryos is initially imprecise. Axonal targeting errors occur along the rostral-caudal and mediallateral tectal axes, and arbors are formed at topographically inappropriate positions. Subsequent course corrections along both tectal axes and large-scale axonal remodeling lead to the retinotopic ordering of terminal arborizations characteristic of the mature projection.

The trajectories and branching patterns of temporal retinal axons labeled with Dil or DiO were determined in whole mounts of retina and tectum from chicks ranging in age from embryonic day 9 to posthatching. Within the retina, labeled retinofugal axons travel in a compact bundle but do not maintain strict neighbor relations, as they course to the optic fissure. The axons enter the contralateral tectum at its rostral edge and grow caudally. Many extend well past their appropriate terminal zone within rostral tectum; a proportion of these later reverse their direction of growth. Many axons grow onto the tectum at incorrect positions along the mediallateral tectal axis. Some correct this error in a directed manner by altering their trajectory or extending collateral branches at right angles. About $80 \%$ of the positional changes of this type are made in the direction appropriate to correct axon position, and thus are likely a response to tectal positional cues. After maturation of retinotopic order, about half of the axons that project to a mature terminal zone have made abrupt course corrections along one or both tectal axes, indicating that initially mistargeted axons can establish appropriately positioned arbors and survive.

The development of temporal axons within the tectum is characterized by 3 phases: elongation, branch and arbor formation, and remodeling. After considerable rostrocaudal elongation, an axon typically develops numerous side branches and arbors, many at inappropriate locations. Most arbors are formed by side branches that develop as inter-

Received Oct. 31, 1988; revised Apr. 20, 1989; accepted May 2, 1989.

This work was supported by grants from the National Eye Institute (EY07025), the McKnight Foundation, and the Sloan Foundation. We thank Dr. James McCasland for help with the statistical analysis.

Correspondence should be addressed to Dr. Dennis D. M. O'Leary, Department of Anatomy and Neurobiology, Box 8108, Washington University School of Medicine, 660 South Euclid Avenue, St. Louis, MO 63110.

a Present address: Department of Biology, Kyoto Prefectural University School of Medicine, Nishitakasukasa-cho 13-2, Taishogun, Kita-ku, Kyoto 603, Japan. Copyright @ 1989 Society for Neuroscience $0270-6474 / 89 / 113776-20 \$ 02.00 / 0$ stitial collaterals; few axons grow directly to their appropriate terminal zone and arborize. Aberrant arbors, and axons and axon segments that fail to form arbors in the appropriate terminal zone, are rapidly eliminated over about a $2 \mathrm{~d}$ period. Axon degeneration appears to play a role in this remodeling process.

Dating back to the pioneering work of Stone $(1941,1944)$ and Sperry $(1943 a, b)$, the retinotectal projection has been the focus of studies of neural specificity and mechanisms involved in the establishment of topographic maps. Much of the work done to date in lower vertebrates, particularly fish and amphibians, has focused on the reestablishment of the retinotopic map by regenerating optic axons. Although much has been learned from these studies, this system does not faithfully recapitulate devclopment (for discussion, scc Sakaguchi and Murphey, 1985; Stuermer, 1988a). To achieve a better understanding of the mechanics of topographic map formation, it is desirable to study developing systems. To carry out detailed studies of this nature, though, it is necessary to label retinal axons in their entirety and to know precisely the region of retina from which the labeled axons originate. This has been accomplished in lower vertebrates with the use of cobalt or modified HRP labeling techniques. Recent studies using these methods in the frog, Xenopus, suggest that the developing retinotectal projection is topographically accurate even at its initial stages of formation (Fujisawa, 1984, 1987; Sakaguchi and Murphey, 1985) confirming the findings of earlier reports (Holt and Harris, 1983; Holt, 1984). Retinotopic order is also present from the onset of development of the retinotectal projection in zebrafish (Stuermer, 1988a), suggesting that this may be a characteristic of lower vertebrates.

Since similar high-resolution anterograde axon tracing studies have not been possible in higher vertebrates, little is known about how topographic order is established in the retinal projections of avians and mammals. There is some evidence, though, that the map is not accurate at early phases of development. Retrograde labeling has indicated that a proportion of retinal ganglion cells in the rat project to topographically inappropriate regions of the superior colliculus (O'Leary et al., 1986). Further, it has been reported that topographic errors occur in the developing chick retinotectal projection on the basis of filling an eye with HRP following a small retinal lesion and finding, 8$48 \mathrm{hr}$ postlesion, no zones devoid of labeling in the tectum (McLoon, 1982). But, because of the inadequacies of the labeling techniques available at the time, little could be inferred about retinal axon behavior over the course of retinotectal map development. However, studies at an order of resolution com- 
parable to those done in fish and frogs can now be carried out in higher vertebrates with the recently introduced fluorescent axon tracer, DiI (Honig and Hume, 1986). DiI locally applied to the chick retina in vivo can label developing retinal axons in their entirety (Thanos and Bonhoeffer, 1987).

We have taken advantage of the sensitivity of Dil as an anterograde axon tracer to examine the establishment of topographic order in the developing retinotectal projection of the chick embryo, focusing on the behavior of axons arising from temporal retina. We chose the chick for several reasons. First, the primary components of its visual system, the eye and optic tectum, are large and readily accessible at all stages of development. Second, the chick visual system is much more differentiated than that of lower vertebrates and its development more closely resembles that of mammals. And third, the chick retinotectal projection has become a choice system for in vitro studies of factors involved in the formation of topographic maps, including the encoding of positional information (Bonhoeffer and Huf, 1980, 1982; Halfter et al., 1981, 1983; Walter et al., $1987 \mathrm{a}, \mathrm{b}$ ) and interactions among retinal axons (Bonhoeffer and Huf, 1985), with which in vivo findings can be related.

We find that in chicks the projection from temporal retina to the optic tectum is initially topographically imprecise. Retinal axons makc significant targeting errors along the 2 major tectal axes, rostral-caudal and medial-lateral, and develop side branches and arbors at aberrant positions within the tectum. The retinotopic precision of terminal arborization characteristic of the mature projection is brought about over a brief period chiefly as a result of 2 processes: course corrections by mistargeted axons and a large-scale elimination of aberrantly positioned axons, axon segments, and arbors. A preliminary account of these findings has been presented elsewhere (Nakamura and O'Leary, 1988).

\section{Materials and Methods}

Animals. Chick embryos of a White Leghorn strain were raised from fertile eggs obtained from Spafas (Roanoke, IL). The eggs were incubated in a forced-draft incubator at $38^{\circ} \mathrm{C}$ and a high relative humidity. On the third day of incubation, most of the embryos were put into "shellless" culture (Auerbach et al., 1974). For this, the egg shell was cleaned with $70 \%$ alcohol, cracked on a sharp metal edge, and the contents poured into a $100 \times 20 \mathrm{~mm}$ sterile, plastic petri dish. The embryos were then raised in a water-jacketed incubator at $38^{\circ} \mathrm{C}$ and a high relative humidity. Raising embryos in this way greatly increases their accessability and does not alter the normal development of the visual system (Auerbach et al., 1974; Thanos and Bonhoeffer, 1983, 1984). A smaller number of embryos were raised entirely in ovo in a forced-draft incubator. These were exposed on the third day of incubation for tracer application at a later stage by making a window in the shell overlying the embryo and sealing it with a transparent tape. Several chicks were allowed to hatch.

Labeling methods. The intensely fluorescent, lipophilic dyes, DiI (1,1'-dioctadecyl-3,3, $3^{\prime}, 3^{\prime}$-tetramethylindocarbocyanine perchlorate; Molecular Probes) and DiO (3,3'-dioctadecyloxacarocyanine perchlorate; Molecular Probes) were used to label ganglion cell axons arising from a small region of retina. The dyes were applied in vivo to a discrete point in peripheral temporal (posterior) retina of embryos raised in ovo for 9-21 d of total incubation (5 were allowed to hatch after labeling) or in petri dishes for 9-19 d of total incubation. For this, a small hole was made in the sclera with a sharp tungsten ncedlc through which a tiny crystal of $\mathrm{DiI}$ or $\mathrm{DiO}$ was inserted into the retina. The labeled embryos were returned to the incubator for a postlabeling period of 1$7 \mathrm{~d}$. At termination, the chicks were decapitated, and their brains and retinas exposed and fixed by immersion in $4 \%$ paraformaldehyde in 0.1 M phosphate buffer $\left(\mathrm{pH} \mathrm{7.4)}\right.$ at $4^{\circ} \mathrm{C}$. The developmental stage of the embryos was determined according to the criteria of Hamburger and Hamilton (1951). Whole mounts of the labeled retina and the contra-

\begin{tabular}{llc}
\hline $\begin{array}{l}\text { Table 1. } \\
\text { fixation }\end{array}$ & Numbers of normal chicks labeled and ages at time of \\
Stage & Age & Number \\
\hline 35 & E9 & 5 \\
36 & E10 & 25 \\
37 & E11 & 24 \\
38 & E12 & 26 \\
39 & E13 & 52 \\
40 & E14 & 34 \\
41 & E15 & 18 \\
42 & E16 & 6 \\
43 & E17 & 5 \\
44 & E18 & 7 \\
45 & E19-20 & 6 \\
$46+$ & Hatched & 5 \\
Total & & 213 \\
\hline
\end{tabular}

lateral optic tectum were made, mounted on glass slides, and coverslipped with a solution of $90 \%$ glycerol and $10 \% 0.1 \mathrm{M}$ phosphate buffer (pH 7.4) to which either $0.1 \%$ phenylcncdiaminc or $5 \% n$-propyl gallatc was added to reduce photobleaching of the fluorescent dye. Prior to whole mounting, incisions were made in the retina and tectum to maintain proper orientation. The coverslipped whole mounts were stored at $-15^{\circ} \mathrm{C}$.

Eight additional embryos were labeled in vitro with $\mathrm{DiI}$ or $\mathrm{DiO}$ as described above on E8 or E10. One day later, in each case the optic nerve emanating from the labeled eye was severed immediately behind the eye with a sharp tungsten needle. The embryos were fixed 1 or $2 \mathrm{~d}$ after nerve transection, and their retinas and tecta were whole-mounted.

Analysis. The whole mounts were examined on a fluorescence microscope equipped with a $100 \mathrm{~W}$ mercury lamp and RITC (DiI) and FITC (DiO) filter cubes. The position of the crystal placement and the trajectory and extent of the labeled axons were plotted on low-power camera lucida tracings of the retinal and tectal whole mounts. Photomontages and more detailed drawings were made of representative cases at various ages. For this, labeled retinal axons were selected and traced under fluorescence illumination at $125 \times$ or $250 \times$ with the aid of a camera lucida and rapidograph pens filled with inks that fluoresce under "black light" illumination. Axon counts were made by examining the specimens with fluorescence microscopy using photomontages as guides. Counting criteria are given in the table legends.

The primary axes of the retina and tectum have been referred to in the literature by different, but synonymous, terms. To avoid confusion, we list here our designations followed by other commonly used, analogous ones. Retina: nasal = anterior; temporal $=$ posterior; dorsal $=$ superior; ventral $=$ inferior. Tectum: rostral $=$ anterior; caudal $=$ posterior; medial $=$ dorsal; lateral $=$ ventral. The designations of the 2 primary axes of the optic tectum, rostral-caudal and medial-lateral, refer to their orientations on E6. The tectal lobes rotate about $90^{\circ}$ counterclockwise between E7 and E13 (Goldberg, 1974).

\section{Results}

We have concentrated on labeling small populations of ganglion cell axons arising from peripheral temporal retina, primarily for 2 reasons. First, this allows us to predict accurately the appropriate terminal zone for the labeled axons on the bases of the detailed topographic map of the mature chick retinotectal projection of Crossland and Uchwat (1979) and the findings that we have obtained from older embryos and posthatched chicks labeled after map maturation. Second, since temporal retina projects to rostral tectum, we are able to assess the occurrence and magnitude of inaccuracies of axon targeting along the rostral-caudal tectal axis.

The numbers of chicks labeled and their age at the time of fixation are listed in Table 1. To allow for direct comparisons, the cases illustrated have very similar crystal placement sites in 


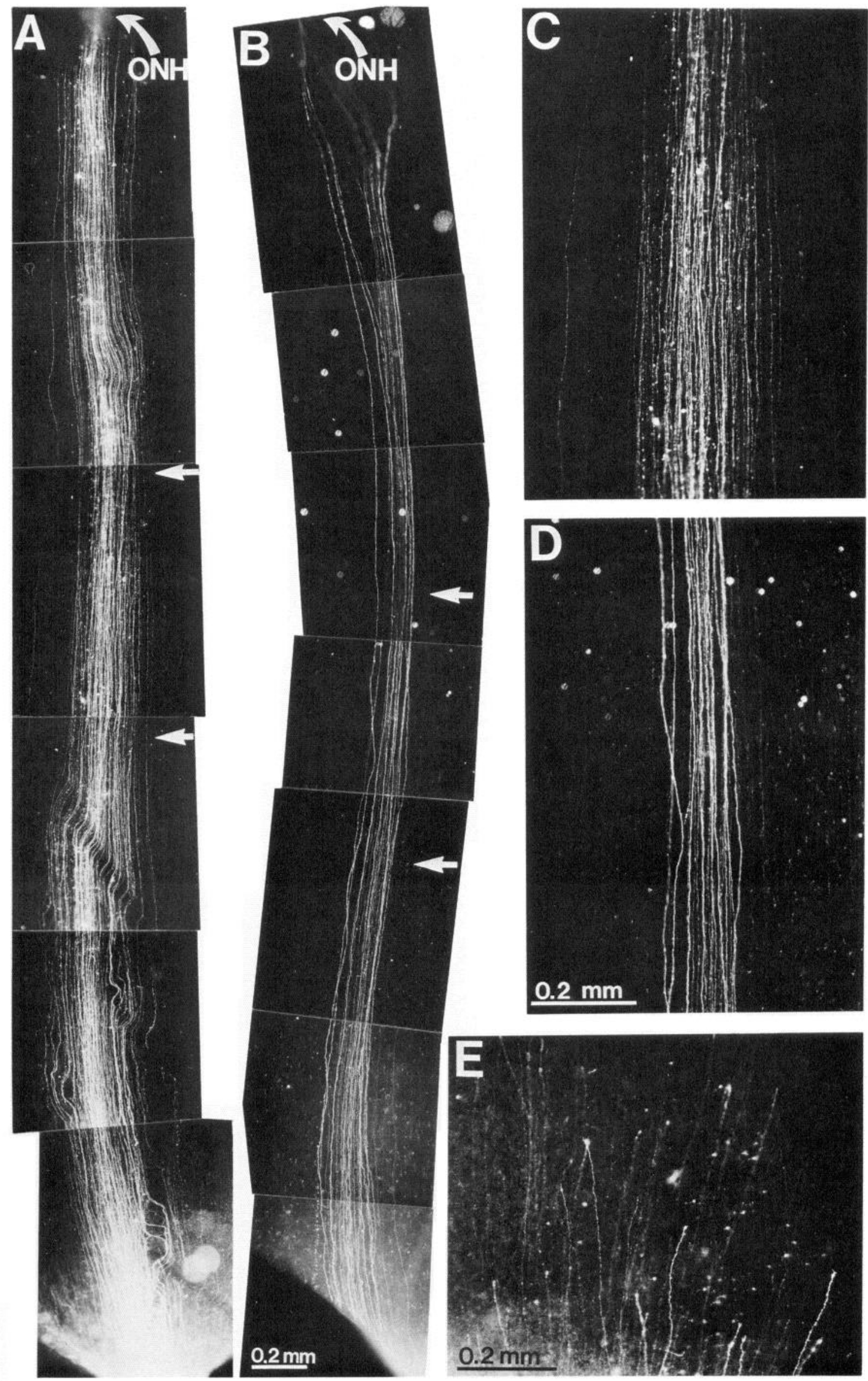


temporal periphery of the right retina, near the dorsal-ventral midline. As described below, and according to the map of Crossland and Uchwat (1979), in the mature chick this region of retina projects to a site close to the rostral border and near the mediallateral midline of the contralateral (left) tectum. We are able to visualize clearly the fluorescently labeled retinal axons and their arborizations since they grow superficially over the tectum within the stratum opticum and arborize immediatcly below this layer within the upper layers of stratum griseum et fibrosum superficiale (SGFS) (Cajal, 1889, 1911; Reperant, 1973). The mature terminal zone appears as a white cloud in the figures due to the intensity of the labeling and the fact that the labeled axons arborize over many focal planes.

\section{Retinal labeling}

The DiI or DiO crystal placed in peripheral temporal retina results in a discrete labeling site which varies between 0.3 to $0.6 \mathrm{~mm}$ in diameter and covers an area equivalent to about $0.03-0.15 \%$ of the surface area of the retina. A compact bundle of labeled axons originates from the labeling site, courses centrally, and enters the optic fissure (Fig. 1, $A, B$ ). Virtually all axons that arise from the labeling site and leave the retina travel in this bundle. Occasionally, a labeled axon does deviate from the bundle but rejoins it either more centrally or at the optic fissure. Within the bundle the axons do not maintain strict neighbor relationships; some crossing over and mixing occurs, although overall the axonal trajectories are roughly parallel (also see Williams and Rakic, 1985). Such mixing is apparent before (Fig. 1, $A, C$ ) and after (Fig. 1, $B, D$ ) maturation of the retinotectal map. We have not observed any branching of retinofugal axons within the retina.

In addition to the axons that leave the retina, labeled fibers tipped with growth cone-like endings radiate from the labeling site in the younger cases and travel for variable distances intraretinally (Fig. 1E). Some of these fibers do branch. These may be normal intraretinal projections or possibly misdirected ganglion cell axons that fail to leave the retina. Long-range retinal interneurons recently described by Catsicas et al. (1987) are also found retrogradely labeled at considerable distances from the crystal site.

\section{Mature projection}

On the basis of morphological criteria, including cytoarchitecture, laminar organization of retinal input, and retinal axon arbor size, with the exception of synaptic density, the chick visual system is considered maturc by E16 (LaVail and Cowan, 1971a; Crossland et al., 1975; Rager, 1980; Thanos and Bonhoeffer, 1987). Not surprisingly, then, we find no significant differences in the appearance of the zone of terminal arborization, nor in the axons that contribute to it, in 29 cases (Table 1) successfully labeled with DiI and examined between E16 (stage 42) and $4 \mathrm{~d}$ posthatching (chicks hatch on E20-21). The mature terminal zones labeled in these cases vary in size between about 0.06 to $0.16 \mathrm{~mm}^{2}$ and cover approximately $0.08-0.2 \%$ of the tectum. Even though these mature terminal zones are comprised of the arborizations of scores of labeled axons, their size is comparable to the mean arbor size of individual axons, 0.07 $\mathrm{mm}^{2}$ (Thanos and Bonhoeffer, 1987). This indicates that the scores of axons arising from the discrete retinal labeling site form a highly focused set of overlapping arbors.

Figure 2 shows a terminal zone near the rostral border and slightly lateral to the medial-lateral midline of the tectum of a newly hatched chick. The chick was labeled in ovo with a crystal of DiI placed $4 \mathrm{~d}$ earlier in peripheral temporal retina near the dorsal-ventral midline, as indicated in Figure 3. The position of the terminal zone is in good agreement with the map of Crossland and Uchwat (1979). In this case, every labeled axon or axon collateral (which number well over a hundred), with the exception of 3 (which are not in the focal plane of Fig. 2), ends and arborizes in the discretely focused terminal zone. The extraterminal zone portions of the axons are bare, and no arbors are found in the tectum outside of the densely labeled terminal zone. The 3 axons which do not project to the terminal zone end with no indication of arborization about $0.4 \mathrm{~mm}$ caudal to the terminal zone. We are confident that the postlabeling survival time was adequate to label these axons in their entirety, since comparable, and even much shorter times, result in the complete labeling of nasal retinal axons projecting to caudal tectum (Thanos and Bonhoeffer, 1987; K. Matsui, H. Nakamura, and D. D. M. O'Leary, unpublished observations). Even though these 3 axons are collaterals of axons that do end in the terminal zone, it is curious that they persist without any apparent terminal arborization of their own. It is possible that they will eventually be eliminated.

Many of the labeled axons project directly to the terminal zone, but a significant proportion attain it by an indirect route (Fig. 2). This indicates that some temporal axons initially make a targeting error but later correct it, either by a turning of the primary axon or by extending a correctly targeted collateral and eliminating inappropriate segments of axon. The course corrections include adjustments along the medial-lateral axis of the tectum (axons 1-3), the rostrocaudal axis (axons 6-8), or along both sets of axes (axons 4 and 5). A number of axons bifurcate and both branches arborize in the terminal zone. Often the branches have similar trajectories (axons 1 and 2), an observation more clearly illustrated in Figure 4.

\section{Development of topographic order in the retinotectal projection}

Temporal retinal axons go through dramatic changes between the time they first grow onto the tectum and the formation of a refined, retinotopically organized projection. By making observations on cases labeled and fixed at progressively later stages, we infer that for each axon these changes occur as a continuous progression over the course of several days and that within a population of axons there is some overlap of events. Nonetheless, it is convenient to consider this period in 3 stages: early, mid, and late phases of map development.

\footnotetext{
Figure 1. Intraretinal DiI labeling. As for all of the photomicrographs, with the exception of Figure $9 A$, these were photographed under RITCfluorescence illumination. $A$ and $B$, Course of DiI-labeled retinofugal axons from the crystal site in peripheral temporal retina (bottom of figure) to the optic nerve head $(O N H)$. $A$ is from a late El3 (stage $39+$ ) embryo labeled prior to the remodeling of the retinotectal projection (from the same case illustrated in Fig. 13); $B$ is from an E15 (stage 41) chick after the major phase of remodeling. Same scale for $A$ and $B$. $C$ and $D$, Higherpower views of the areas marked by arrows in $A$ and $B$, respectively. Same scale for $C$ and $D$. $E$, Labeled fibers tipped with growth cone-like endings radiate from the Dil crystal site in an E11 (stage 37 ) retina.
} 


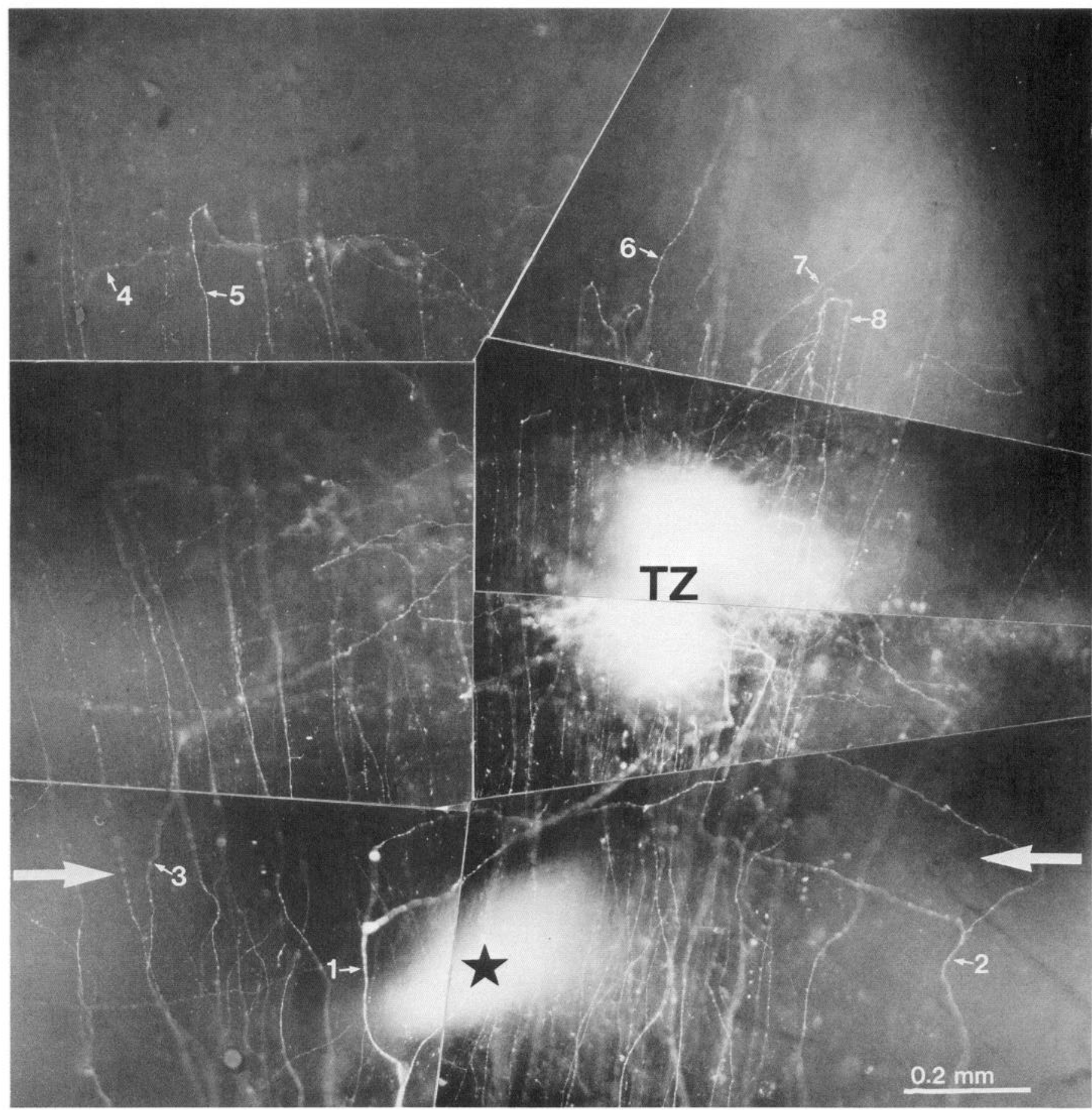

Figure 2. Mature terminal zone DiI-labeled peripheral temporal axons in a tectal whole mount from a newly hatched chick (stage 46) labeled $4 \mathrm{~d}$ before fixation. The large arrows mark the junction of the optic tract and the rostral border of the optic tectum. The terminal zone (TZ) is located within tectum, near its rostral border. The star marks a terminal zone within the tectal gray nucleus which lies along the optic tract. Arborizatons in the terminal zones are out of focus because they lie deep to stratum opticum, the retinal axon layer. Caudal is to the top, lateral to the right. Also see companion Figure 3.

\section{Early phase: axonal extension with overshooting of terminal} zone

Retinal axons first reach the tectum on E6 (Crossland et al., 1975). These axons, which originate from central retina, begin to arborize within central tectum by E9 (Rager and von Oeynhausen, 1979; Thanos and Bonhoeffer, 1987). In our study, we consider the development of axons arising from peripheral temporal retina, which lag behind those from central retina largely because of the central to peripheral gradient of ganglion cell genesis (Kahn, 1973) and maturation (Weysse and Burgess, 1906; Goldberg and Coulombre, 1972; Rager, 1980).

We find that axons from the temporal periphery have grown onto the tectum by E9 (stage 35). Early on E10 (stage 36) many 

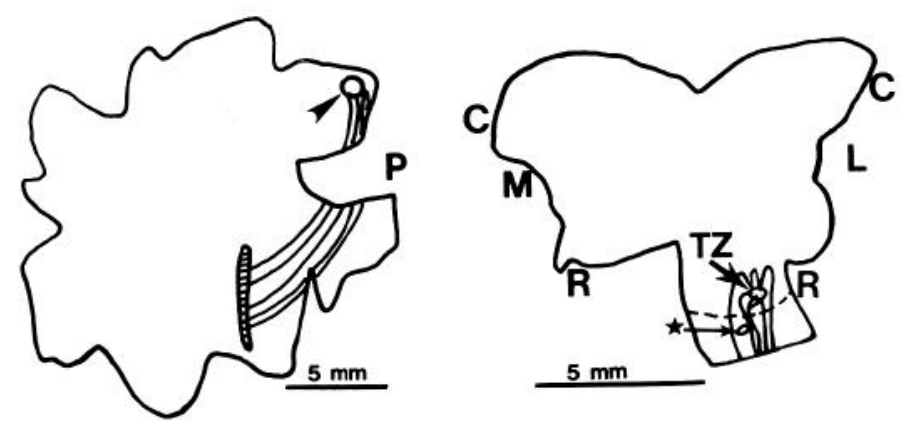

Figure 3. Tracings of retinal and tectal whole mounts from the case shown in Figure 2. The crystal site in the retina is marked with an arrowhead on the tracing on the left, and the trajectory of the labeled axons to the optic nerve head is diagrammed (dorsal is to the top). On the other tracing, the tectal terminal zone is indicated with $T Z$ and the tectal gray nucleus terminal zone with a star. The dashed line marks the junction of rostral tectum with the optic tract. Abbreviations: $A$, anterior (nasal); $C$, caudal; $L$, lateral; $M$, medial; $P$, posterior (temporal); $R$, rostral.

temporal axons have already extended caudally well past their appropriate terminal zone in rostral tectum (Figs. 5 and 6). The axonal trajectories are orderly and fairly parallel to one another. The axons are tipped with growth cone-like endings; side branches are rarely observed (Fig. 5). At this, and subsequent ages, the labeled temporal axons are distributed over $2 \mathrm{~mm}$ or more across the medial-lateral axis of rostral tectum; occasional axons are found well outside of this range. This distribution is overly extensive relative to the proportion of retina from which the axons originate and the width of their future terminal zone, indicating that many enter the tectum at an incorrect position. Given the compact bundling of the labeled retinofugal axons over their intraretinal course, this error must arise predominantly as the result of axon mixing within the optic nerve, chiasm, or tract. An occasional axon (\#1, Fig. $5 A$ ) makes a right angle turn at its leading edge, altering its position along the mediolateral tectal axis.

\section{Midphase: widespread development of axon branches and arbors}

This phase, which loosely spans E11-E13 (stages 37-39), is characterized by a continued caudal growth of axons labeled from peripheral temporal retina and their elaboration of collateral branches and arbors both within and well outside of the region of tectum appropriate for their terminal zone. These observations are illustrated in Figure 7 with an E12 (stage 38) embryo which had DiI and DiO crystals placed at the same site in peripheral temporal retina (Fig. 8), just dorsal to the dorsal-ventral midline $3 \mathrm{~d}$ prior to fixation. In this case, the majority of labeled axons overshoot their appropriate terminal zone by $1-3 \mathrm{~mm}$ along the rostral-caudal axis (which measures about $10 \mathrm{~mm}$ ), some extending $5 \mathrm{~mm}$ or more past it, and arbors develop over a wide area of tectum. The labeled axons do not extend any significant distance into the caudal half of tectum (see Fig. 7 with reference to Fig. 8).

Most arbors are produced by collateral branches of the primary axons. These branches typically develop and extend at right angles along much of the length of the primary axons. Since we find little or no indication of branch formation at stages when the parent axons have grown an appreciable distance rostrocaudally over the tectum, it is likely that many of the col-

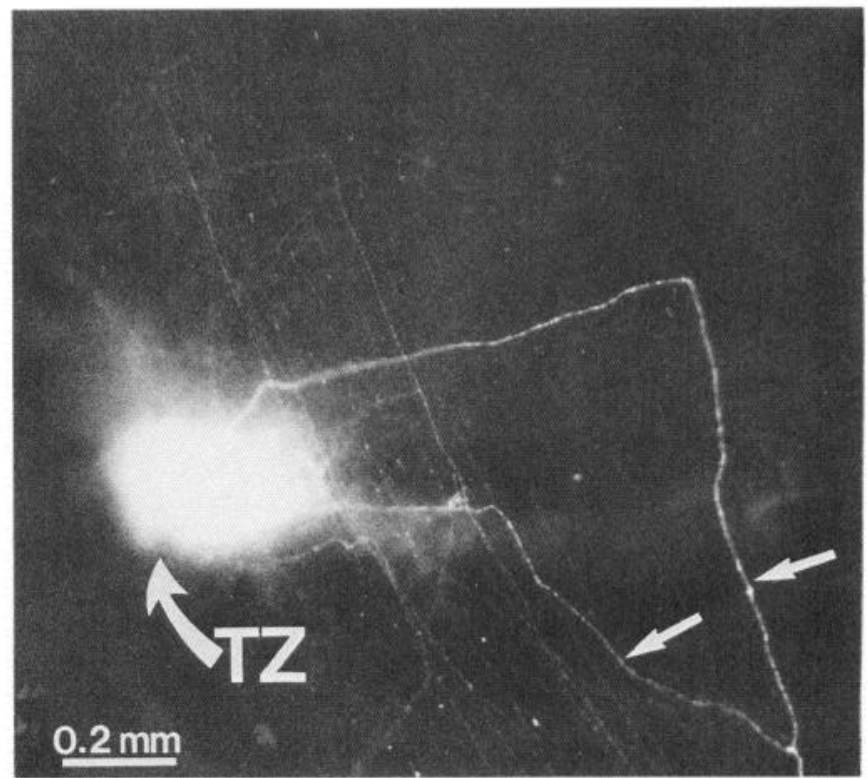

Figure 4. A mature terminal zone $(T Z)$ in a tectal whole mount from an E18 (stage 44) chick labeled with a DiI crystal placed in peripheral temporal retina in ovo $2 \mathrm{~d}$ before fixation. The arrows point to 2 branches of a bifurcate axon which make similar course changes and arborize in the TZ. Caudal is to the top; lateral to the right.

lateral branches develop by an interstitial budding from the axon shaft, rather than from a growth cone remnant left behind or by growth cone bifurcation. This process may be related to the phenomenon of "back-branching," which plays a role in the formation of terminal arbors of Xenopus retinotectal axons (Harris et al., 1987), or to that of the interstitial budding of axon branches described for primary cortical axons as a means of developing collateral projections to multiple subcortical targets (O'Leary and Terashima, 1988). Many branches immediately extend deep to stratum opticum and arborize (Fig. 10, $C, D$ ), while others first grow along the medial-lateral tectal axis for some distance. Some branches also form and grow caudally paralleling the parent axon. Virtually all axons form numerous branches and arbors along their length (Fig. 9, also see Figs. 7 and $10, C, D)$. Arbors that develop in aberrant positions are not perceptively different from those of equivalent stages of development found in the region of tectum approximating the appropriate terminal zone. The density of arborization, though, is greatest within the region of tectum that seems appropriate for the mature terminal zone (Fig. 10), but this region of densest arborization is considerably larger than that which will be covered by the mature terminal zone. This observation may reflect a decline along the rostral-caudal tectal axis in the number of labeled axons. Only a small proportion of the axons form a terminal arbor at their distal end (Fig. 10, $A, B$ ).

\section{Late phase: map remodeling with elimination of aberrant axons and arbors}

The late phase of map development is characterized by a largescale, rapid remodeling of the retinotectal projection resulting in the formation of a highly focused terminal zone. A substantially refined projection resembling that of mature chicks emerges by E15-E16. This is illustrated in Figure 11 with an embryo fixed on E15 (stage 41) and labeled in vitro $3 \mathrm{~d}$ earlier with a Dil crystal placed in peripheral temporal retina, near the dorsal- 


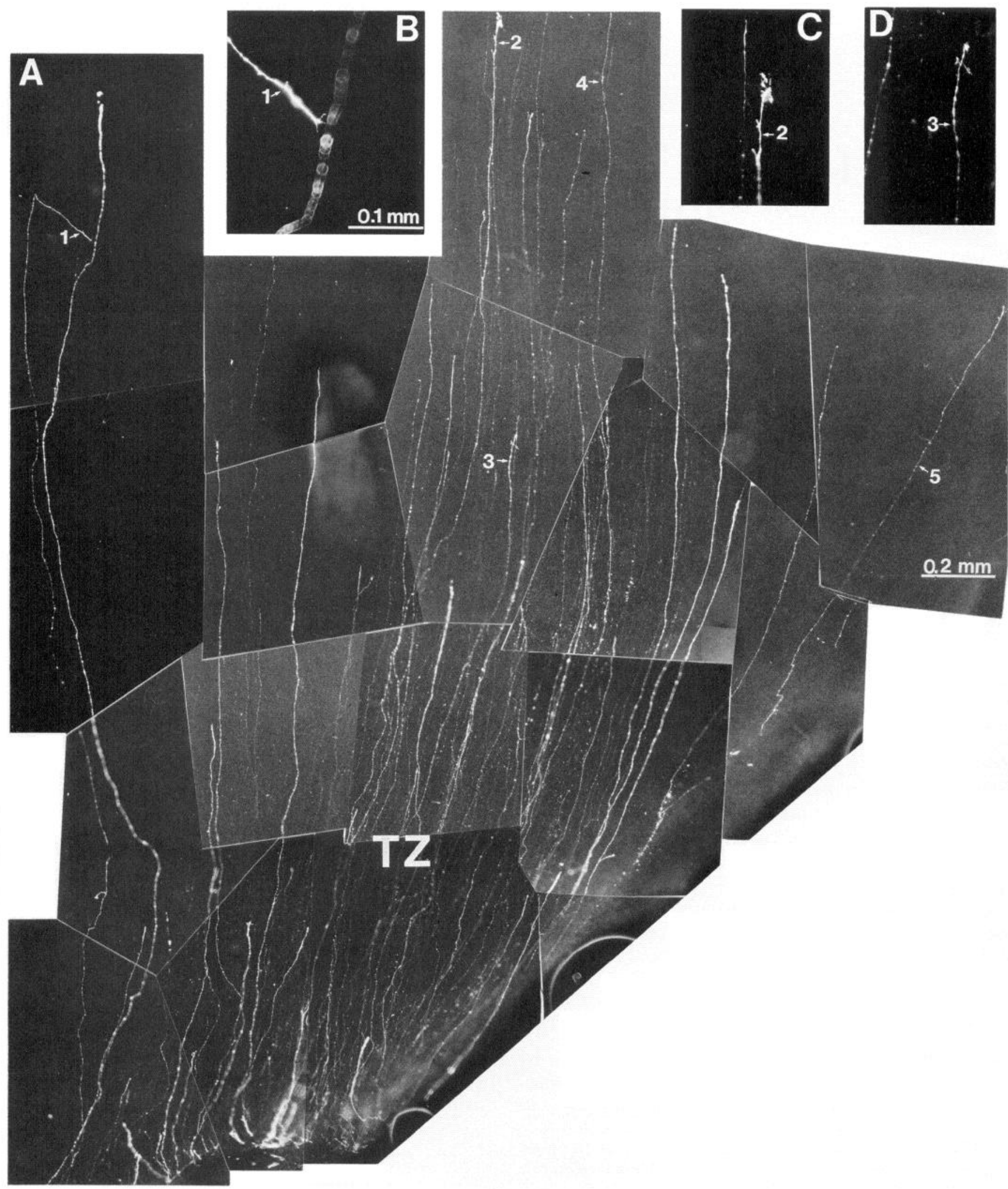

Figure 5. Early overshooting of appropriate terminal zone by temporal axons. A, Temporal retinal axons extending over the surface of a tectal whole mount from an early E10 (stage $36-$ ) chick labeled in vitro $2 \mathrm{~d}$ before fixation. $T Z$ marks the approximate site of the future, appropriate terminal zone. Several axons extend caudally out of the field (for example, 4). Caudal is to the top, lateral to the right. $B-D$, Higher-power views of growth cone-like endings of 3 axons indicated by numbers. Scale bar same for $B-D$. Also see companion Figure 6 . 
ventral midline (Fig. 12). The labeled axons form arbors strictly confined to a dense cluster located near the rostral border of tectum just lateral to the midline of the medial-lateral tectal axis. The axons possess no side branches, or at most a rare short one, outside of the terminal zone. Only a very small number of axons or collaterals that do not end in the terminal zone remain.

An important point to make here is that in every case the labeling pattern and the degree of topographic precision are entirely related to the developmental age of the chick at the time of fixation, regardless of the embryo's age at time of labeling and the postlabeling survival period within the range used. For example, the embryo illustrated in Figure 11 was labeled on E12, a stage at which the retinotectal projection is diffuse. However, the labeling pattern in the tectum is essentially indistinguishable from that we observe in chicks labeled on E15 and allowed to survive for $1-7 \mathrm{~d}$ but is very different from chicks labeled for comparable or longer periods and fixed before E15.

Aberrantly positioned arbors, and essentially all axons and axon collaterals that fail to establish an arbor within the appropriate terminal zone, are eliminated over a period of about $2 \mathrm{~d}$. There is an indication that at least some of the aberrant projections are removed through degeneration. In normal embryos fixed on E14 and labeled with DiI or DiO 1-4 d earlier, the labeling in the tectum has 2 distinct appearances. As in embryos fixed at other ages, we find seemingly healthy, well-labeled axons, but we also see a substantial amount of dye-labeled debris that has the appearance of axons and arbors in the process of breaking up (Fig. 13). The fact that the presence of dye-labeled "degeneration debris" is independent of postlabeling survival time, but rather is related to the age at fixation, suggests that it is not due to a death of ganglion cells injured by crystal placement.

To support our supposition, we DiI- or DiO-labeled normal embryos on either E8 $(n=2)$ or E10 $(n=5)$ and cut the optic nerve of the labeled eye $1 \mathrm{~d}$ later to induce retinal axon degeneration. The chicks were fixed $1 \mathrm{~d}$ after nerve transection, on E10 and E12, respectively, ages at which we observe little or no "degeneration" in normal embryos. As shown in Figure 14, the DiI labeling in the tectum contralateral to the transected optic nerve has an appearance that resembles the "degenerating axons" labeled in normal E14 embryos. Neither the DiI-labeled debris nor the small number of intact labeled axons present 1 $\mathrm{d}$ after nerve transection are apparent in an E13 experimental chick labeled on E10 and fixed $2 \mathrm{~d}$ after nerve transection. This suggests that the debris from axon degeneration is rapidly removed, as seems to occur in normal chicks.

\section{Corrections of axon-targeting errors along primary tectal axes and evidence for trajectory changes in response to positional cues}

On average, about half of the temporal axons that persist to maturity attain their terminal zone by making an abrupt course correction (Table 2; also see Figs. 2, 11, 12). The position of these axons prior to their change in trajectory reflects a targeting error along one or both of the tectal axes. About $40 \%$ of temporal axons correct an error along the medial-lateral axis. It is not unusual to find axons that alter their original position along the medial-lateral axis by a millimeter or more to attain their terminal zone (Fig. 15, axons 1 and 2). The medial-lateral distribution of temporal axons which project to a mature terminal zone is about $2 \mathrm{~mm}$, which is similar to that seen at earlier stages. About $23 \%$ of temporal axons that survive overshoot

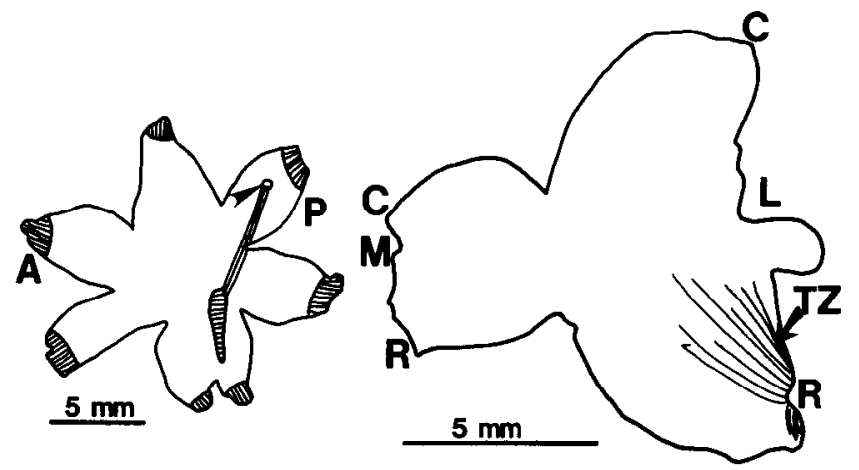

Figure 6. Tracings of retinal and tectal whole mounts from the case illustrated in Figure 5. The tracing on the left shows the position of the DiI crystal in the retina (marked by arrowhead) and the course of the labeled axons. Dorsal is to the top. The approximate position of the appropriate future terminal zone $(T Z)$ and the trajectory and extent of the labeled axons is shown on the tracing of the tectum on the right. See Figure 3 for abbreviations.

the terminal zone along the rostral-caudal axis, a few by nearly a millimeter, reverse their course, and return to it. About $15 \%$ of temporal axons correct their position along both axes to reach the terminal zone.

These observations made after map maturation do not, in themselves, indicate that the course-correcting axons responded in a directed fashion to positional cues associated with the tectum. Although temporal axons and their collateral branches do not wander about the tectum in search of their appropriate terminal zone, as regenerating retinal axons in frogs seem to do (Fujisawa et al., 1982), it is possible that the retinal axons randomly extend branches and only those branches that form arbors in a correct position are retained. We have addressed this issue by examining the response of peripheral temporal axons to an incorrect position along the mediolateral tectal axis in $8 \mathrm{embryos}$ ranging in age from late E10 to E12. Over this period, temporal axons make right angle turns at their leading edge and extend within stratum opticum collateral branches at roughly right angles to their rostrocaudal direction of growth (Fig. 16). The direction of axon turns and collateral branches over $50 \mu \mathrm{m}$ in length and within $800 \mu \mathrm{m}$ on either side of the assumed appropriate position of the terminal zone was scored as either appropriate or inappropriate to correct axon position along the medial-lateral tectal axis (Tables 3 and 4). A significantly greater number of these course changes are made in a direction that corrects axon position ( $t$ test, $t=5.312, p<0.001$ ), with a range of 70-87\% correct for the 8 cases analyzed. Overall, we scored 268 turns and collateral branches and found that $77 \%$ are made in the correct direction. No difference is seen in the percentage of correct responses made by axons displaced medial or lateral to the appropriate point (76 vs $78 \%$ ). The number of correct and incorrect turns and branch extensions was also analyzed for $200 \mu \mathrm{m}$ intervals from the appropriate point and found to vary between 72 and $87 \%$. Again, the number of correct responses is significantly greater than incorrect ones ( $t$ test, $t=2.79, p<$ 0.05 ). These data indicate that the direction of a trajectory change or long collateral branch extension is not random but rather seems to be a directed response that corrects axon position.

\section{Discussion}

We have studied the events that lead to the development of a refined, topographically ordered projection from temporal retina to rostral tectum. Temporal retinal axons show an early lack 


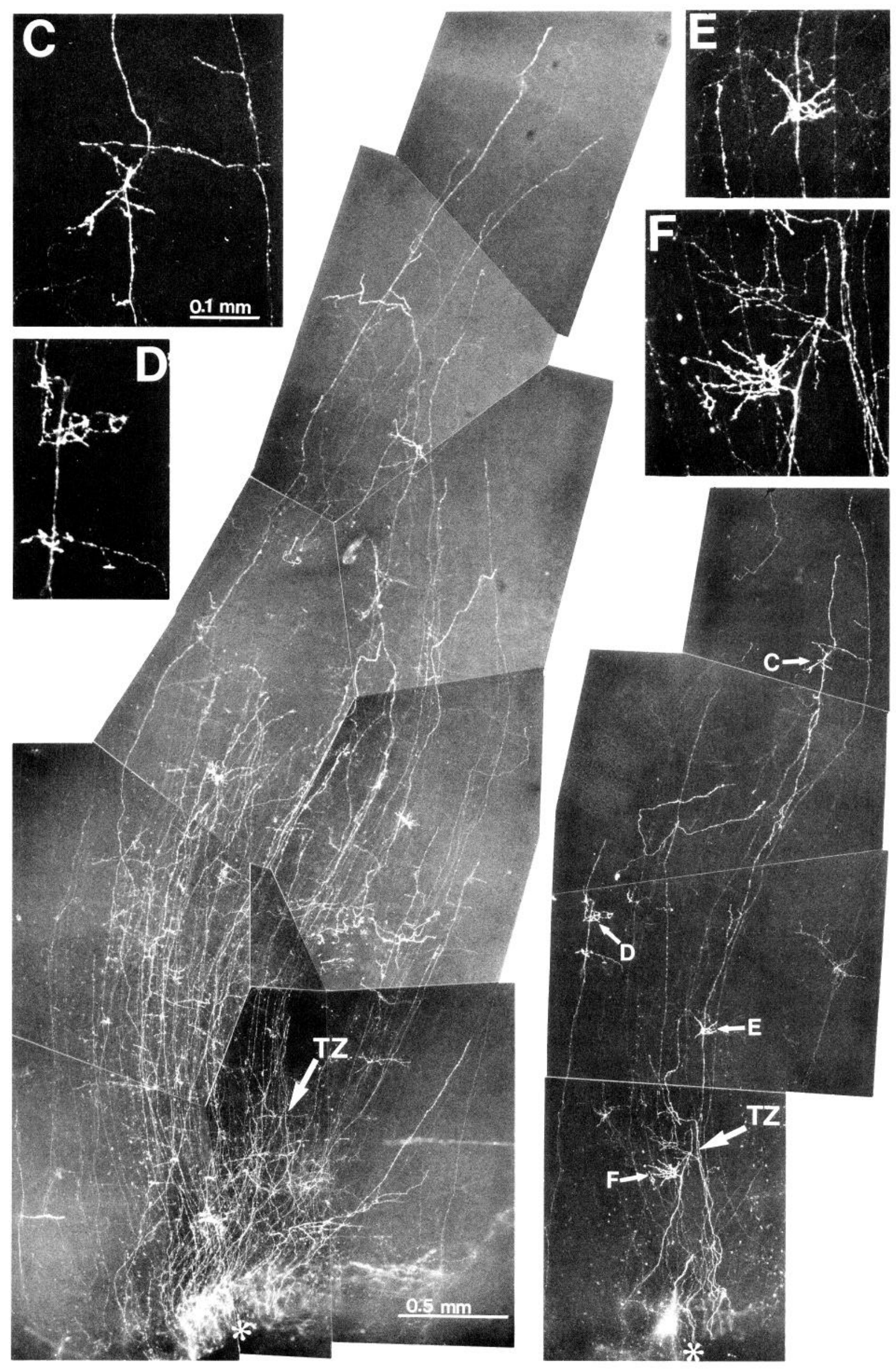




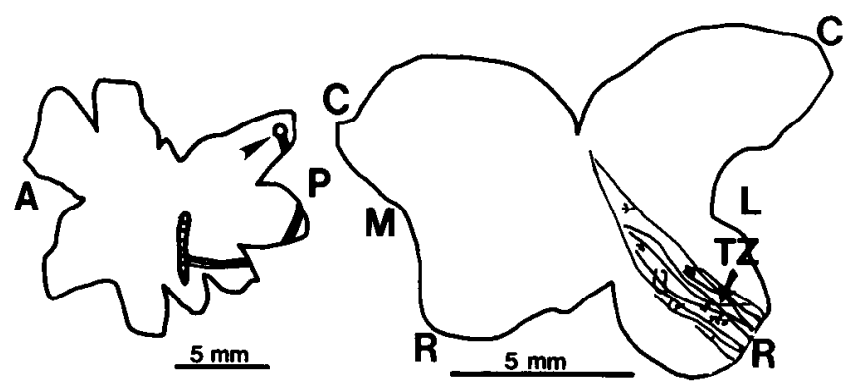

Figure 8. Tracings of retinal and tectal whole mounts from the case illustrated in Figure 7. The tracing at left shows the site of placement of the DiO and DiI crystals and the course of labeled axons to the optic nerve head. Dorsal is to the top. The approximate position of the appropriate terminal zone $(T Z)$ and the trajectory and extent of the labeled axons is shown on the tracing on the right. See Figure 3 for abbreviations.

of topographic accuracy, not only in their targeting along the 2 primary tectal axes, but also in arbor formation. Temporal axons commonly enter the tectum at an incorrect position along the medial-lateral tectal axis, and, as they grow caudally across the tectum, most extend well past the appropriate rostrocaudal position of their terminal zone. Collateral branches and arbors are formed along the length of the axons, often in very aberrant locations. The development of topographic order evolves out of course corrections by growing axons and the large scale elimination of mistargeted axons, axon segments, and aberrantly located axonal arbors. Figure 17 illustrates the 3 major stages that temporal retinal axons go through en route to maturation: elongation, widespread branch and arbor formation, and remodeling.

Our study also provides the first demonstration of the tectal trajectories taken by a group of axons which arise from a small cluster of retinal ganglion cells and project to a common terminal zone. About half of the axons that project to the mature terminal zone make a major course correction along one or both of the 2 primary tectal axes. The ways in which temporal axons attain their appropriate terminal zone are illustrated in Figure 18. This summary illustration presents a compilation of our observations of temporal axons during development and following maturation.

\section{Consideration of the early disordered retinotectal projection}

The demonstration that developing retinal axons initially overshoot their appropriate terminal zone along the rostral-caudal tectal axis hinges on the ability to predict its approximate location. By labeling axons arising from a region of retina near the dorsal-ventral midline of the temporal periphery, which at maturity projects to a position near the rostral border of tectum, close to its medial-lateral midline (Crossland and Uchwat, 1979; present observations), we remove the ambiguity in our prediction because these points are easily determined within both the retina and tectum. However, even if we erred in our prediction, a substantial proportion of temporal axons certainly grow well past their appropriate terminal zone since many extend for a

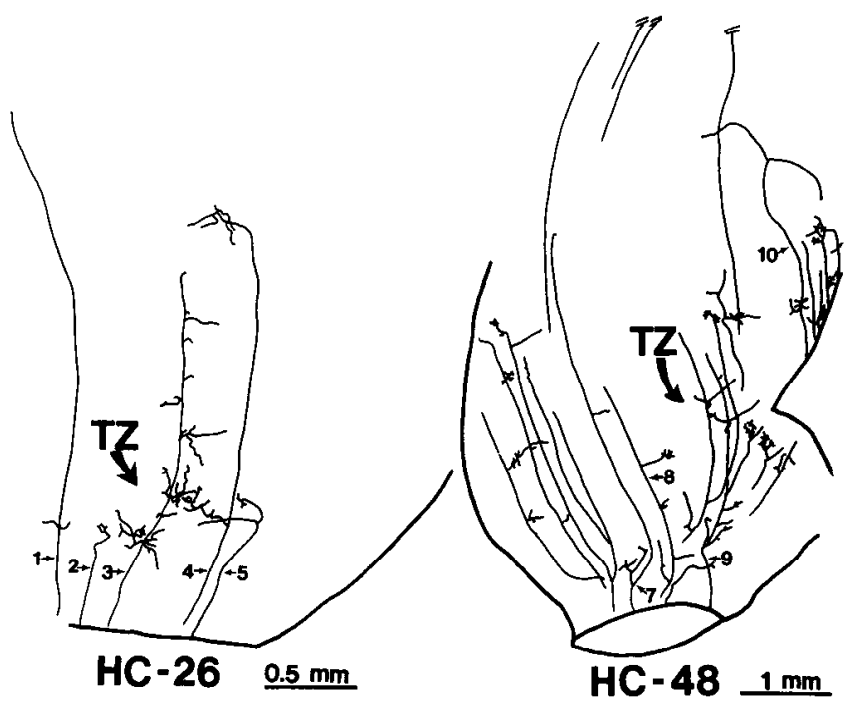

Figure 9. Camera lucida tracings of representative retinal axons in tectal whole mounts from 2 E13 (stage 39) chicks labeled in vitro with DiL crystals placed in the peripheral temporal retina either $4 \mathrm{~d}(\mathrm{HC}$ 26) or $6 \mathrm{~d}(\mathrm{HC}-48)$ before fixation. The approximate position of the appropriate terminal zone is marked $T Z$. Most of the axons make multiple arbors and/or side branches (see, for example, axons 3 and 9). Caudal is to the top.

considerable distance across the tectum. That topographic imprecision occurs along the rostral-caudal tectal axis is supported by our finding of an early widespread distribution of side branches and arbors rostrocaudally over the tectum. Positional inaccuracies along the medial-lateral tectal axis are obvious given that the labeled axons spread out to cover $2 \mathrm{~mm}$ or more of the medial-lateral extent of the tectum, an extensive distribution relative to the size of the retinal labeling site and the mediallateral dimension of the typical mature terminal zone labeled in this study (ranging from about 250 to $450 \mu \mathrm{m}$ ).

Two technical factors that could plausibly account for our findings should be addressed. First is the possibility that axons arising from other, distant regions of the retina are labeled by DiI or DiO crystals displaced from the original placement site. However, we carefully scanned the retinas for ectopic, secondary labeling sites and found none. Further, all labeled axons that leave the eye originate from the single identified crystal placement site and enter the optic fissure at the same place. All of these axons, with rare exceptions, travel in a compact bundle along this intraretinal course. Second, perhaps axons arising from other retinal regions are secondarily labeled by dye transfer within the optic nerve or tract. We find no evidence for this manner of labeling. If axons become labeled in this way, we would expect that they would also be labeled along their intraretinal course back to their parent ganglion cells since DiI is an excellent retrograde axonal label (Honig and Hume, 1986; Catsicas et al., 1987). This concern can be most effectively ruled out by our determination that the pattern of labeling in the tectum was independent of the survival time within the range

Figure 7. Widespread distribution of temporal retinal axons and arborizations. DiO- (left montage) and DiI- (right montage) labeled retinal axons in a tectal whole mount from an E12 (stage 38) chick labeled in vitro $3 \mathrm{~d}$ before fixation. DiO crystals and a smaller DiI crystal were placed at the same site in peripheral temporal retina. The asterisks on the montages mark the same point at the rostral border of the tectum. $T Z$ points to the approximate position of the appropriate terminal zone. Caudal is to the top, lateral to the right. $C-F$, Higher-power views of the arbors indicated on the right montage. Axon $D$ forms 2 small arbors, marked with arrowheads in $D$. Also see companion Figure 8. 

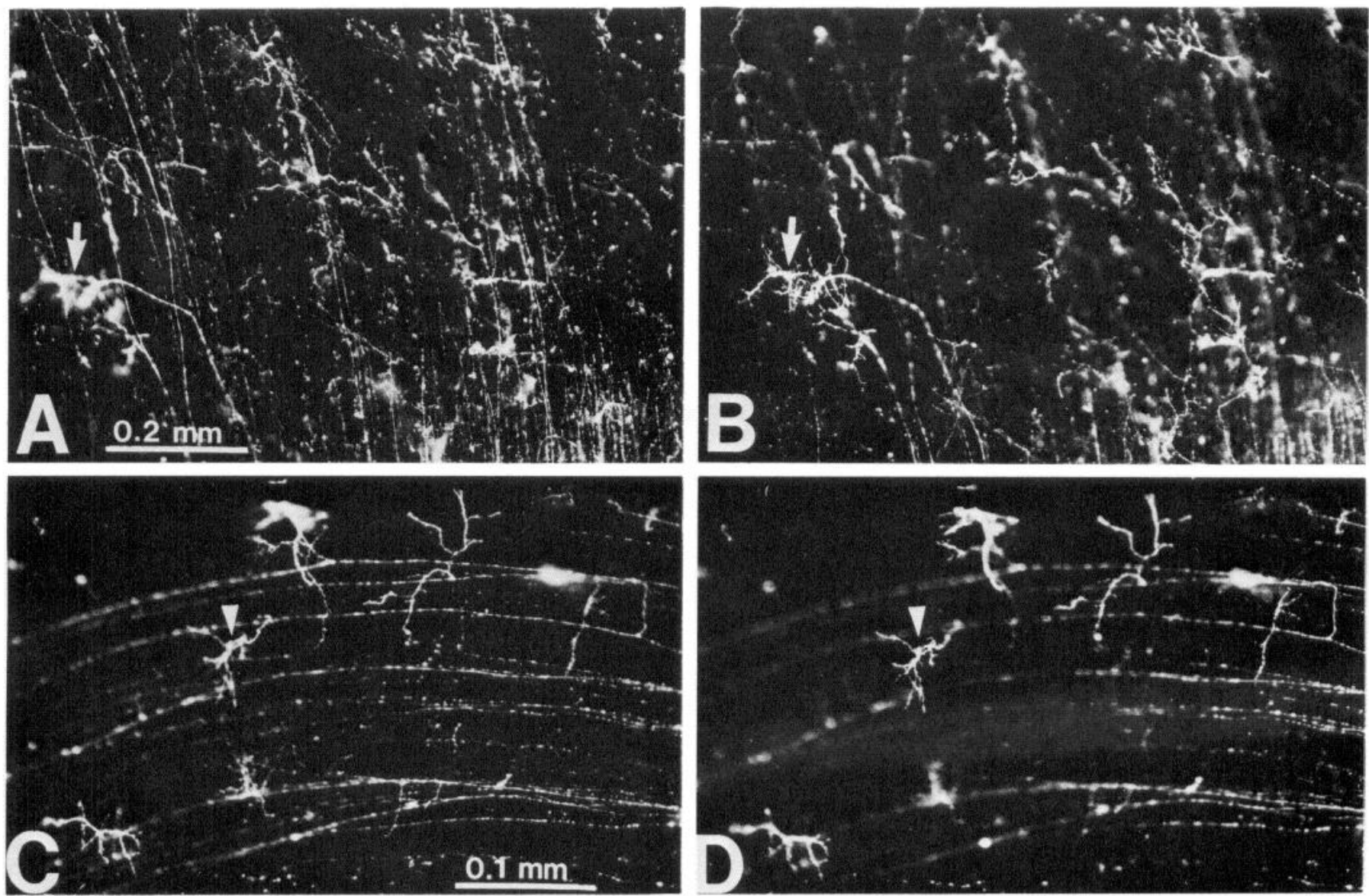

Figure 10. Early arborization is more profuse in the appropriate region of tectum. Retinal axons and arbors in a tectal whole mount from a late E13 chick (stage $39+$ ) labeled with a DiI crystal placed in peripheral temporal retina slightly dorsal to the dorsal-ventral midline 3 d prior to fixation. $A$ and $B$, Two focal planes of the same field within the tectal region approximating the appropriate terminal zone. The arrow indicates the same arbor in the 2 photos. This arbor is formed at the terminal (distal) end of the axon. Caudal is to the top. $C$ and $D$, Two focal planes of the same field $5 \mathrm{~mm}$ caudal to that shown in $A$ and $B$. The arrowhead points to an arbor made by a short collateral branch of an axon. The same axon extends another branch (near the right side of $C$ and $D$ ) which also forms an arbor, but out of the plane of focus. Caudal is to the right.

\section{Table 2. Course corrections made by retinal axons to attain mature terminal zone}

\begin{tabular}{|c|c|c|c|c|c|c|c|}
\hline Case & $\operatorname{Axons}^{\alpha}(n)$ & $\%$ Medial $^{b}$ & $\%$ Lateral $^{c}$ & $\begin{array}{l}\% \text { Overshoot } \\
\text { no M-L } \\
\text { error }{ }^{d}\end{array}$ & $\begin{array}{l}\% \text { Overshoot } \\
\text { with M-L } \\
\text { errore }\end{array}$ & $\begin{array}{l}\% \text { Overshoot } \\
\text { total }\end{array}$ & $\begin{array}{l}\% \text { Total } \\
\text { correc- } \\
\text { tion }^{g}\end{array}$ \\
\hline 1 & 51 & 28 & 12 & 8 & 12 & 20 & 47 \\
\hline 2 & 24 & 21 & 29 & 13 & 8 & 21 & 63 \\
\hline 3 & 57 & 18 & 25 & 5 & 11 & 16 & 47 \\
\hline 4 & 98 & 36 & 10 & 6 & 15 & 21 & 52 \\
\hline 5 & 40 & 28 & 18 & 5 & 28 & 33 & 50 \\
\hline 6 & 47 & 19 & 11 & 19 & 11 & 30 & 49 \\
\hline Mean & $53 \pm 23$ & $25 \pm 6$ & $17 \pm 7$ & $9 \pm 5$ & $14 \pm 6$ & $24 \pm 6$ & $51 \pm 6$ \\
\hline
\end{tabular}

The trajectories of labeled axons arising from a small region of retina and projecting to a mature, discrete terminal zone were determined in 6 chicks ranging from E16 to posthatching. Axons that abruptly alter their position by more than $200 \mu \mathrm{m}$ along either the medial-lateral or rostral-caudal tectal axes in a manner necessary to attain the terminal zone are scored as making a course correction.

${ }^{a}$ Total number of labeled axons projecting to the terminal zone.

${ }^{b}$ Percentage of labeled axons displaced medial to the appropriate position prior to the trajectory change.

' Percentage of labeled axons displaced lateral to the appropriate position prior to the trajectory change.

${ }^{d}$ Percentage of labeled axons, correctly positioned along the medial-lateral axis, that grow beyond the terminal zone along the rostral-caudal tectal axis and later reverse their direction of growth.

e Percentage of labeled axons that are in error along both the rostral-caudal and medial-lateral axes and later correct their course.

${ }^{f}$ Total percentage of labeled axons that grow past the terminal zone along the rostral-caudal tectal axes and later correct their course.

STtal percentage of labeled axons that correct a targeting error to attain a mature terminal zone. 


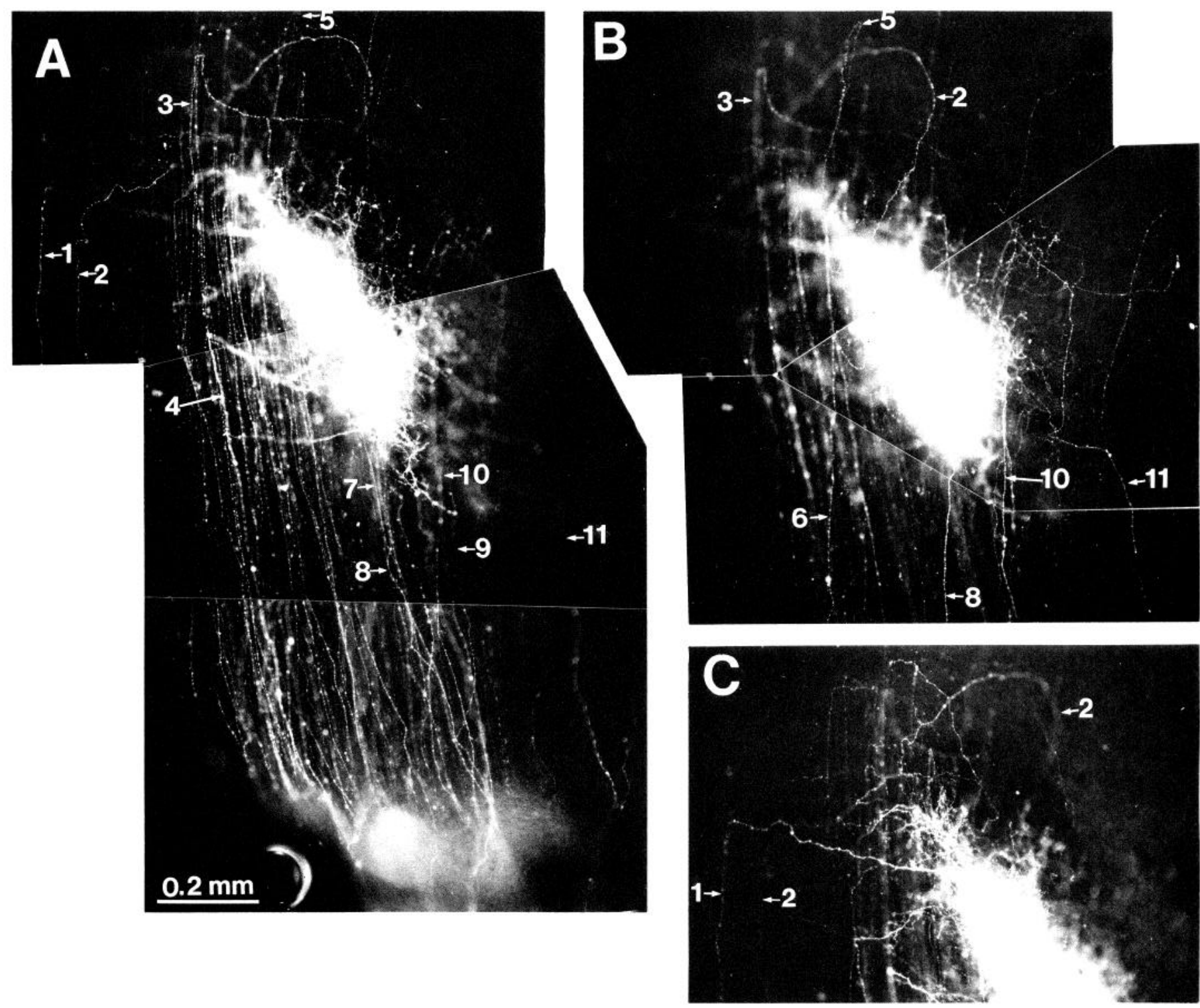

Figure 11. Three focal planes $(A-C)$ of DiI-labeled temporal axons and their terminal zone near the rostral tectal border in a whole mount of the tectum from an E15 (stage 41) chick labeled in vitro $3 \mathrm{~d}$ before fixation. Caudal is to the top, lateral to the right. Also see companion Figure 12 .

of 1-7 d used and was entirely related to the developmental age of the embryo at the time of fixation.

Two important observations are inconsistent with either of the 2 technical concerns considered above and strongly support our contention that the developing retinotectal projection is topographically imprecise. The first is that individual, developing retinal axons go through a transient phase during which they possess side branches and arbors along much of their length. The second is that after map maturation about half of the labeled axons that arise from a cluster of retinal ganglion cells and terminate together at a discrete point on the tectum have made an obvious correction of an earlier targeting error.

\section{Remodeling of the initially diffuse projection}

The extensive remodeling of the initially imprecise chick retinotectal projection is not an aberration resulting from a considerable and rapid expansion of the tectum. We mention this because in developing frogs (Sakaguchi and Murphey, 1985) and fish (Stuermer, 1988a) retinal axonal arbors, although much smaller in absolute size than in the adult, cover a greater percentage area of tectum than they will at later stages. This agerelated decrease in arbor coverage is due to a very substantial growth of the tectum relative to retinal arbors, rather than arbor retraction. However, the chick tectum is generated by a flurry of neurogenesis essentially confined to an interval spanning E4E9 (LaVail and Cowan, 1971b), unlike the tecta of frogs and fish which continue to add neurons throughout life (Gaze et al., 1974; Raymond and Easter, 1983), and does not change perceptibly in size over the very brief period during which the aberrant axons and arbors are eliminated (LaVail and Cowan, 1971a; Kelly and Cowan, 1972). Over the same period that aberrant arbors are eliminated in the chick, mean arbor size increases by about $40 \%$ and stabilizes (Thanos and Bonhoeffer, 1987). Thus, unlike in frogs and fish, an individual arbor comes to cover a greater, albeit very small, percentage of the surface area of the tectum (about $0.2 \%$ ). 

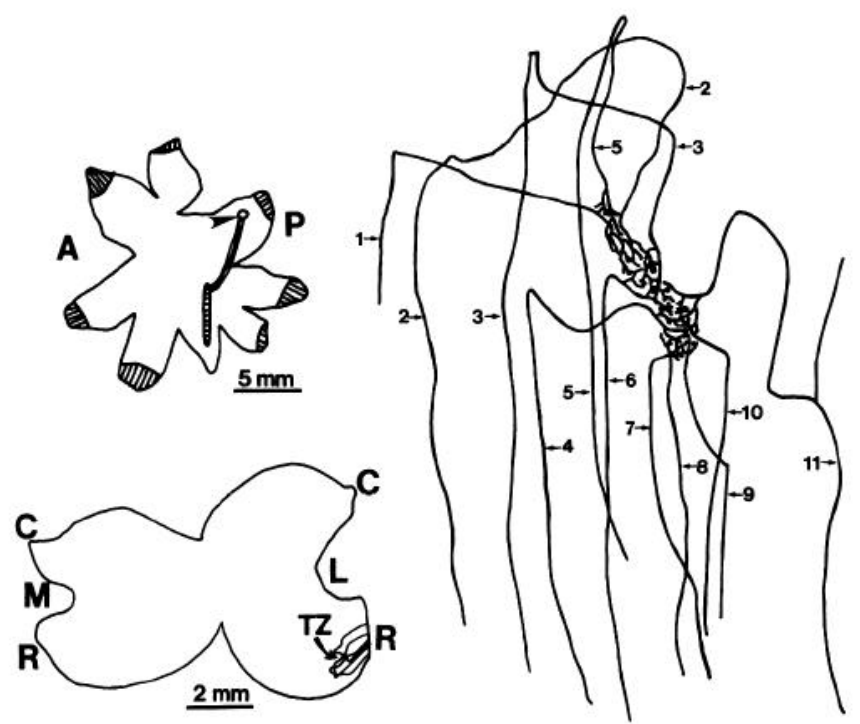

$0.2 \mathrm{~mm}$

Figure 12. Tracings from the same case as that illustrated in Figure 11. The DiI crystal site (arrowhead) and the course of the labeled axons to the optic nerve head are indicated on the tracing of the retinal whole mount (upper left). Dorsal is to the top. The terminal zone $(T Z)$ and the course of the labeled axons to it are shown on the drawing of the tectal whole mount (lower left). The tracing on the right is of selected DiI-labeled retinal axons that project to the terminal zone; the same axons are also indicated by numbers in Figure 11. For abbreviations see Figure 3.
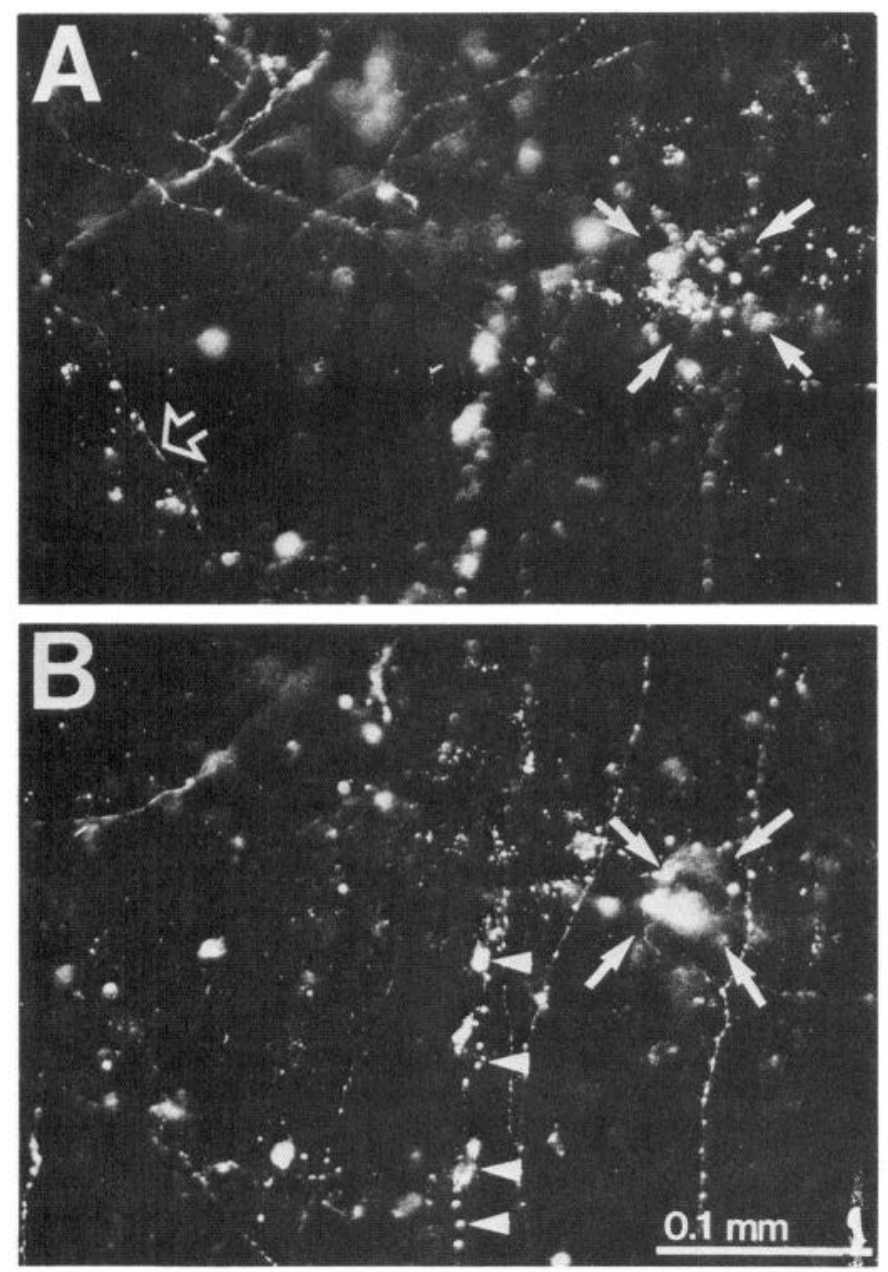
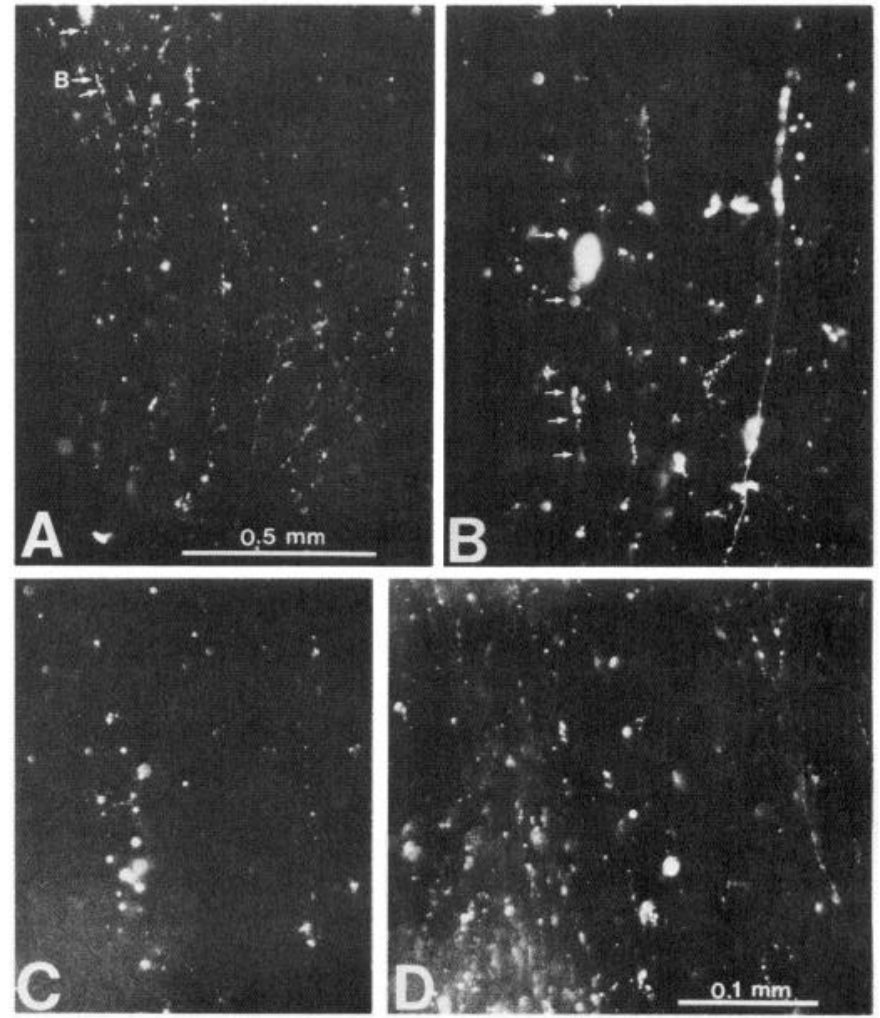

Figure 14. The appearance in tectal whole mounts of induced degeneration of retinal axons prelabeled with DiI prior to optic nerve transection. $A$ and $B$, From an E10 chick labeled with a DiI crystal placed in peripheral temporal retina on E8. The optic nerve was cut on E9. A, Low-power view of a field of DiI-labeled debris that is seemingly the result of induced axon degeneration. $B$, Higher-power view of the upperleft-hand corner of $A$ (labeled $B$ ). One example of what seems to be a degenerating DiI-labeled axon is marked by arrows in $A$ and $B . C$ and $D$, From an E1 2 chick labeled with a DiI crystal in peripheral temporal retina on E10. The optic nerve was cut on E10. Same scale bar for $B-$ $D$. Caudal is to the top.

It is difficult to bracket precisely the period of map remodeling since events that increase its diffuseness, for example, the continued growth of mistargeted axons and the formation of aberrantly located collateral branches and arbors, overlap with those that contribute to the establishment of topographic order, such as axonal course corrections and remodeling. Further, these events are likely to vary regionally along the central to peripheral maturational gradient of the retina (Kahn, 1973; Rager, 1980). For the population of temporal axons that we have studied, the major phase of map remodeling involving the removal of incorrectly targeted axons and arbors appears to begin late on E13 and be essentially complete by E15. Since this period coincides with the phase of retinal ganglion cell loss in the chick (Rager and Rager, 1978; Hughes and McLoon, 1979), it is tempting to speculate that the axons which form very aberrant projections

\section{$\leftarrow$}

Figure 13. $A$ and $B$, Different focal planes of a region of a tectal whole mount caudal to the appropriate terminal zone to show a DiI-labeled axon (marked by arrowheads in $B$ ) and its arbor (marked by arrows in $A$ and $B$ ) that appear to be degenerate. The open arrow in $A$ points to a healthy-appearing axon. Taken from an E14 (stage 40) chick labeled in vitro with a DiI crystal placed in peripheral temporal retina $4 \mathrm{~d}$ before fixation. Caudal is to the top. 

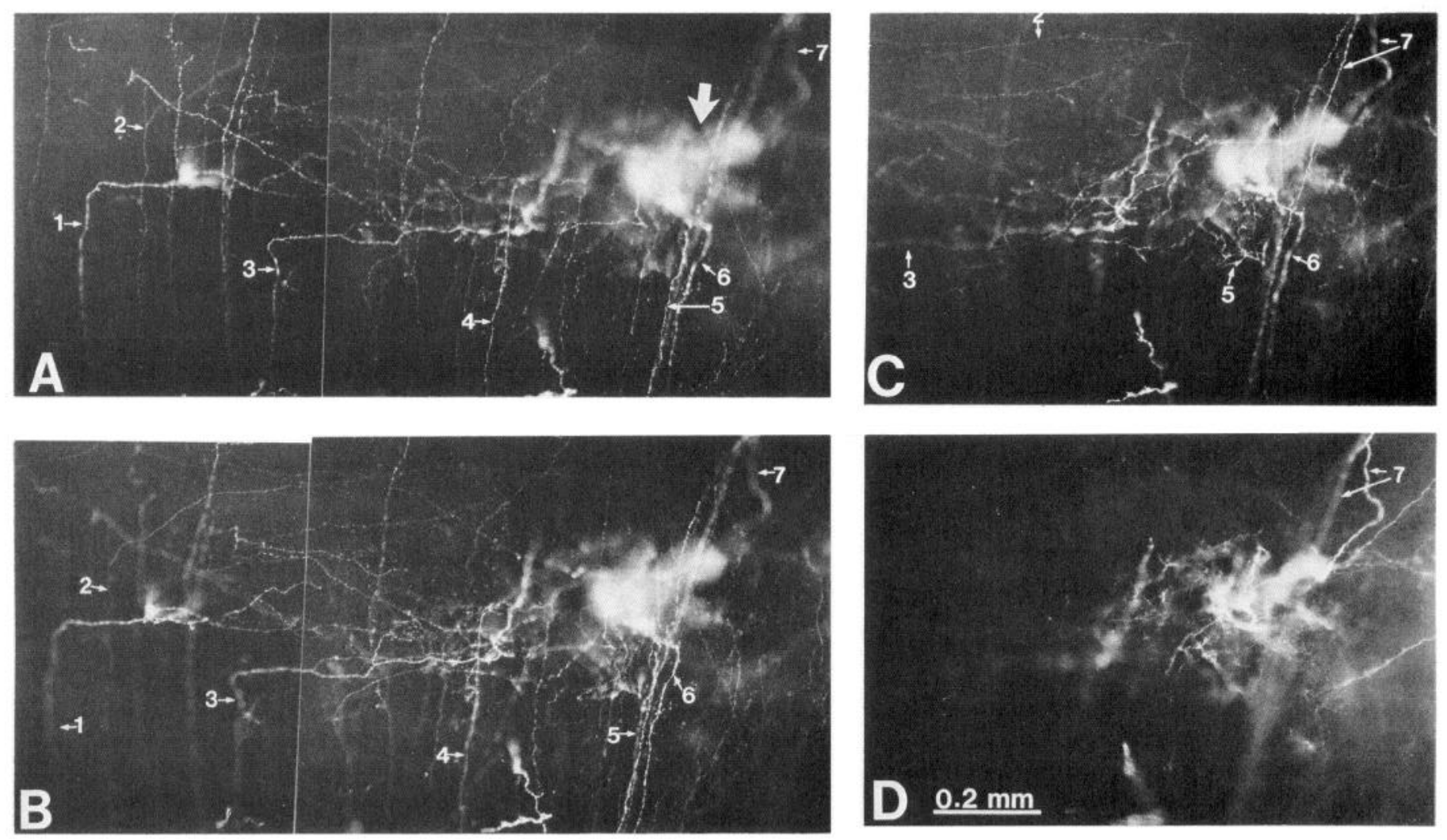

Figure 15. Four focal planes of a near maturation terminal zone (marked by large arrow) and axons that project to it. Taken from a tectal whole mount of an E16 chick labeled with a DiI crystal placed in peripheral temporal retina $2 \mathrm{~d}$ before fixation. Caudal is to the top, lateral to the right. Axons $1-4$ make trajectory changes to correct a positional error along the medial-lateral tectal axis. Axons 5 and 6 grow directly to the terminal zone, whereas axon 7 overshoots it but makes a $180^{\circ}$ course change and returns.

are removed through a selective loss of the ganglion cells that give rise to them. Such a mechanism has been suggested to account for the removal of a small retinal projection to the ipsilateral tectum of chicks which occurs over the same period (McLoon and Lund, 1982; O'Leary et al., 1983; Thanos and Bonhoeffer, 1984). Selective ganglion cell death has been shown to operate in rats where it plays a role in the refinement of topographic order in the developing retinocollicular projection (O'Leary et al., 1986) and serves to eliminate other classes of erroneously projecting ganglion cells (Bunt et al., 1983; Insausti et al., 1984; O'Leary, 1987).
It is conceivable, though, that a considerable amount of the remodeling is achieved by a selective removal of aberrant segments of axons that also establish a projection to the correct region of tectum. In mammals, the selective elimination of major axonal branches without loss of the parent cell has been shown to be a viable mechanism for the remodeling of axons with widely targeted collaterals (Innocenti, 1981; O'Leary et al., 1981; Stanfield et al., 1982). On a more local scale, branch elimination from specific regions of the terminal portions of retinal axons leads to the laminar arrangement of retinogeniculate arborizations (Sretevan and Shatz, 1986). In lower ver-

Table 3. Course corrections made along the medial-lateral tectal axis by growing axons: data from individual cases

\begin{tabular}{|c|c|c|c|c|c|c|c|c|}
\hline \multirow[b]{2}{*}{ Parameter } & \multicolumn{8}{|c|}{ Case } \\
\hline & 1 & 2 & 3 & 4 & 5 & 6 & 7 & 8 \\
\hline No. of turns $s^{a}$ & 23 & 47 & 35 & 48 & 17 & 30 & 35 & 33 \\
\hline No. correct & 16 & 41 & 26 & 36 & 14 & 21 & 27 & 25 \\
\hline No. incorrect & 7 & 6 & 9 & 12 & 3 & 9 & 8 & 8 \\
\hline$\%$ correct & 70 & 87 & 74 & 75 & 82 & 70 & 77 & 76 \\
\hline
\end{tabular}

Eight late E10-E12 embryos were used for this analysis. Axon turns and side branches longer than $50 \mu \mathrm{m}$ and within $800 \mu \mathrm{m}$ medial or lateral to the assumed appropriate position of the future terminal zone were scored as correct if growth was in the direction appropriate to correct axon position along the medial-lateral tectal axis and incorrect if it was in the opposite direction. The medial-lateral position of the future terminal zone was assigned as the midpoint of a 1600 $\mu \mathrm{m}$ wide zone that encompassed the highest density of labeled axons. This data passed the Wilk-Shapiro test of normality $(p<0.05)$. The number of turns that are correct is significantly greater than the number that are incorrect, with the mean percentage of $76.4 \pm 5.4$ (Student's $t$ test for unequal variances, $t=5.31, p<0.001$ ).

${ }^{a}$ Number of turns and side branches scored. 


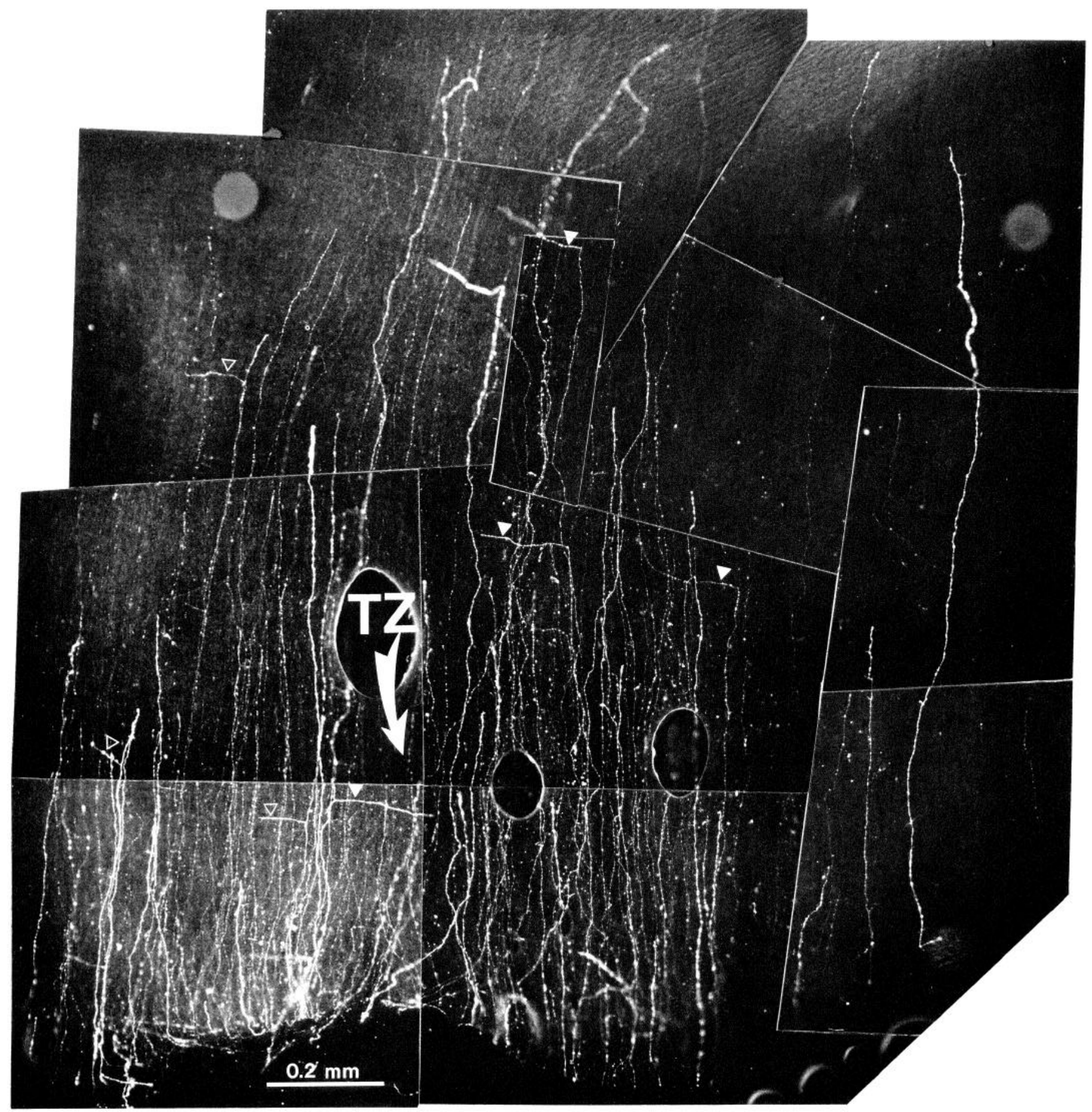

Figure 16. Growing temporal axons make trajectory changes which alter their position along the medial-lateral tectal axis. Taken from a whole mount of a late E10 (stage $36+$ ) chick labeled with a DiI crystal placed in peripheral temporal retina $2 \mathrm{~d}$ before fixation. The approximate position of the appropriate terminal zone is indicated by $T Z$. The medial-lateral position of the terminal zone was assumed to be the midpoint of the distribution of labeled axons along the medial-lateral axis (isolated axons more peripherally located were ignored). Four examples of axons scored as making a trajectory change or branch extension in a direction appropriate to correct their position along the medial-lateral tectal axis are marked with solid, small arrowheads. Three examples made in a direction opposite that appropriate to correct their position are marked with small, open arrowheads.

tebrates, a similar mechanism appears to play a predominant role in establishing retinotopic order in the regenerating retinotectal projection (Fujisawa et al., 1982; Becker and Cook, 1987), as well as maintaining order as retinal connections shift their positions across the tectum in response to the continuous, but disparate, growth of the retina and tectum throughout life (Fujisawa, 1987). In these latter instances, the aberrant axon branches appear to degenerate (Fujisawa et al., 1982; Fujisawa, 1987). Our similar observation in the chick that aberrant axons and arbors seem to degenerate is compatible with both selective 


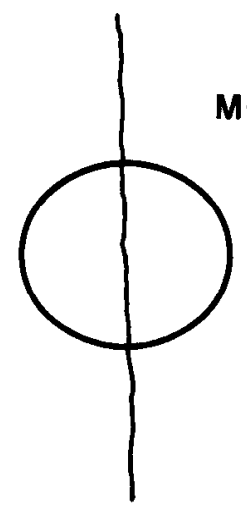

EARLY ELONGATION
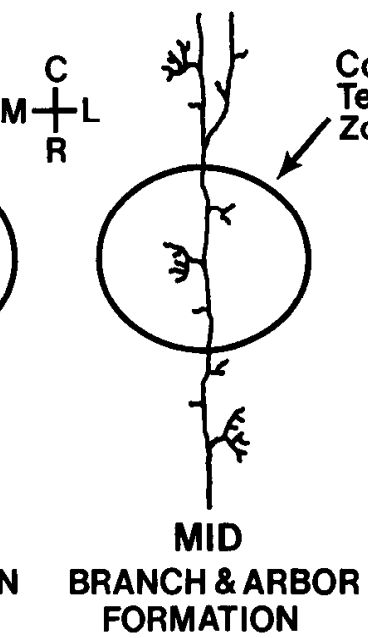

FRANCH \& ARBOR
FORMATION

Figure 17. Schematic diagram summarizing 3 major developmental stages of a typical retinotectal axon, elongation (early), branch and arbor formation ( $m i d$ ), and remodeling (late). During the early stage, the typical retinal axon enters the rostral edge of the tectum and extends caudally past its appropriate terminal zone. At this stage, the axon is bare and does not possess side branches or arbors. During the midstage, the axon develops numerous short side branches alongs its length and elaborates arbors in regions of tectum appropriate and/or inappropriate for its mature connection. Finally, by the late stage, remodeling is achieved through the loss of inappropriate side branches and aberrant arbors. See Figure 3 for abbreviations.

ganglion cell loss and axon branch elimination as mechanisms of retinotectal map remodeling.

The large-scale remodeling of the chick retinotectal projection cannot be accounted for by a shifting of connections of the sort documented in frogs (Gaze et al., 1974; Fraser, 1983; Reh and Constantine-Paton, 1984; Fujisawa, 1987) and fish (Easter and Stuermer, 1984). In frogs and fish, the terminal shifting is a continuous, slow and orderly advancement of established retinal arbors across the tectum throughout the life of the animal. The period over which the chick retinotectal projection is remodeled is far too brief to allow for any significant contribution from this mechanism, although a related one could be used to relocate to a more favorable position arbors that are initially established close to the appropriate terminal zone. If early-arriving central retinal axons behave similarly to the later-arriving peripheral retinal axons studied here, the observations which prompted the suggestion that chick retinotectal connections shift during development (McLoon, 1985) would likely reflect an early lack of topographic specificity in arbor formation by central retinal axons rather than a progressive shifting of their connections from rostral to central tectum.

\section{Directional responses of retinal axons along primary tectal axes}

The appropriate site of arborization of retinal axons within the optic tectum is usually defined in terms of position along the 2 primary tectal axes, rostral-caudal and medial-lateral, with a third coordinate, a laminar or radial one, that is less often considered. It is hypothesized that retinal axons locate their appropriate terminal zone along the 2 primary axes on the basis of positional markers in the form of distinct molecules present on the surfaccs of tcctal cclls that are recognized by a complementary set of molecules present on retinal growth cones (Sperry,

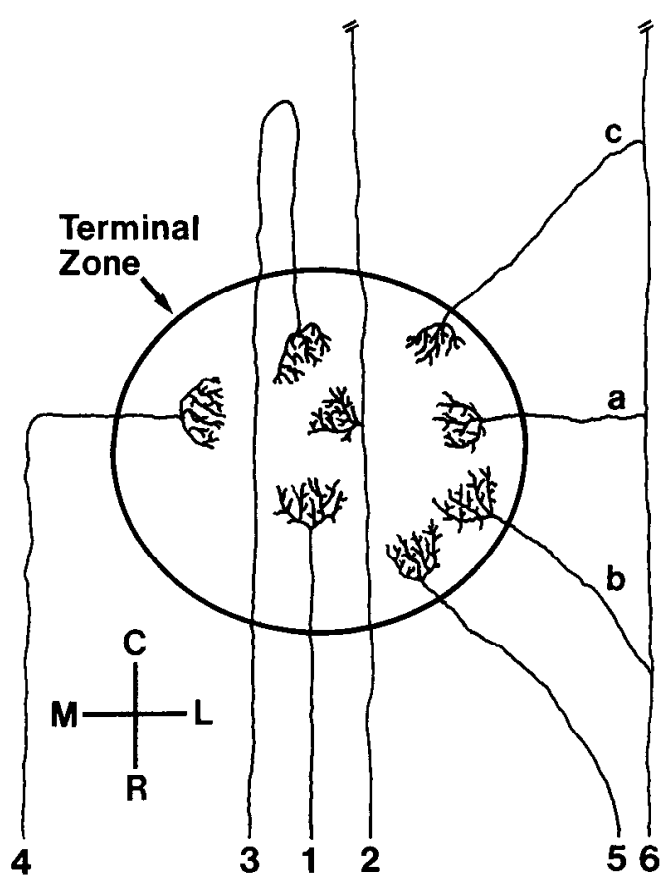

Figure 18. Schematic diagram summarizing the ways retinal axons appear to attain the appropriate terminal zone. A minority of axons grow directly to the terminal zone, stop, and form a terminal arbor (axon 1). Most extend caudally past the terminal zone and form a branch which develops an arbor within the terminal zone (axons 2 and 6 ); the axon segment caudal to the correctly targeted branch is later eliminated. Axons that pass through the terminal zone extend a branch deep into the retinorecipient layers which then forms an arbor (axon 2), whereas those that enter the rostral tectum at an incorrect position along the medial-lateral tectal axis often sprout a side branch which extends some distance within stratum opticum before arborizing (axon 6). The side branches are usually extended by the parent axon after it passes the appropriate terminal zone and can form at a position directly apposite to the terminal zone (axon $6 a$ ) or at a point rostral or caudal to it (axon $6 b, c)$. Segments of the axon beyond a correctly targeted branch point are later lost. A fair proportion of axons correct a medial-lateral error by changing their direction of growth at their distal tip abruptly (axon 4 ) or, less often, gradually (axon 5). Some axons overshoot the terminal zone, reverse their direction of growth and reenter it (axon 3). See Figure 3 for abbreviations.

1963). A widely accepted variation of this concept proposes that terminal addresses along the rostral-caudal and medial-lateral tectal axes are determined by graded distributions of molecules with complementary gradients present along the corresponding retinal axes (Fraser, 1980; Gierer, 1981, 1983, 1987; Bonhoeffer and Gierer, 1984). Evidence from in vitro assays (Bonhoeffer and Huf, 1982; Walter et al., 1987a) is consistent with this concept of a graded distribution of positional molecules.

Our findings, though, suggest that a large proportion of temporal retinal axons initially do not respond to the hypothetical markers which encode position along the rostral-caudal tectal axis, as many grow well beyond the rostral-caudal position of their appropriate terminal zone. A number of possibilities could account for this apparent lack of recognition. First, the growth cones of the retinal axons may not be competent to respond to cues identifying the appropriate terminal site. This seems unlikely since in vitro experiments have demonstrated that growth cones of temporal retinal axons can clearly distinguish between monolayers of cells (Bonhoeffer and Huf, 1982) or membrane fragments (Walter et al., 1987a) prepared from rostral versus 
Table 4. Course corrections made along the medial-lateral tectal axis by growing axons: data for $200 \mu \mathrm{m}$ intervals from appropriate position

\begin{tabular}{lllll} 
& \multicolumn{4}{l}{ Interval } \\
\cline { 2 - 5 } Parameter & $0-200$ & $200-400$ & $400-600$ & $600-800$ \\
\hline No. of turns & & & & \\
No. correct & 83 & 98 & 64 & 23 \\
No. incorrect & 64 & 76 & 46 & 20 \\
\% correct & 19 & 22 & 18 & 3 \\
& 77 & 78 & 72 & 87
\end{tabular}

The data from the 8 cases presented in Table 3 is summed here, but divided into $200 \mu \mathrm{m}$ intervals on either side of the appropriate position of the future terminal zone. A turn or side branch is placed in the interval that corresponds to the position of the axon medial or lateral to the future terminal zone before the turn or side branch was initiated. This data passed the Wilk-Shapiro test of normality $(p<$ 0.05 ). The number of turns that are correct is significantly greater than the number that are incorrect (Student's $t$ test for equal variances, $t=2.79, p<0.05$ ).

a Number of turns and side branches scored.

caudal tectum. Second, the cues may not be present at the time the axons grow over rostral tectum. However, the preference of temporal axons for rostral membrane fragments in in vitro assays is strongest between E6 and E10 (Walter et al., 1987a). Although the developmental role of this regional discrimination remains to be determined, it nevertheless indicates that molecular distinctions between tectal regions are present throughout the period that retinal axons grow onto the tectum. A third possibility is that temporal axons which extend beyond their correct terminal zone do so because their growth cones do not appropriately contact positional markers. This could be due to the tendency of temporal axons to be positioned superficially within the optic fiber layer (Thanos and Bonhoeffer, 1983), and thus displaced from the retinorecipient layers of the tectum. Reportedly, position within stratum opticum seems to affect the targeting abilities of experimentally disordered retinal axons (Thanos et al., 1984). To determine if axon position within stratum opticum is an important variable for accuracy of axonal targeting during normal development, it would be necessary to examine the behavior of axons originating from central retina. These are the first retinal axons to reach the tectum and grow closest to the retinorecipient layers.

Some developing axons that initially extend caudally past their appropriate terminal zone subsequently reverse their direction of growth and locate their appropriate terminal. Over $20 \%$ of the axons that terminate in a mature terminal zone have corrected an initial overshoot along the rostral-caudal axis. However, these observations alone are insufficient to decide whether trajectory reversal is an active course correction in response to positional cues.

The response of axons to an incorrect position along the medial-lateral axis does seem to be a directed behavior. Many temporal axons enter the tectum at points along the mediallateral axis inappropriate for the site of their future terminal zone; an error introduced after the axons exit the eye. As with rostral-caudal overshoots, this class of targeting error is apparent not only during development, but also following map maturation: over $40 \%$ of the axons that terminate in the mature terminal zone have made a significant trajectory change to correct a positional error along the medial-lateral axis. Developing temporal axons most often alter their medial-lateral position by making a right angle turn or by extending a collateral branch along the medial-lateral axis, orthogonal to the rostrocaudal growth of the primary axon. A significantly greater number of these changes of medial-lateral position, amounting to about $80 \%$ of the total, are made in the direction appropriate to correct the positional error. It seems unlikely, then, that this behavior simply amounts to a random sampling of the tectum. A qualitatively similar finding has been reported for chick embryos in which intraretinal injections of anti-NCAM Fab' fragments were used to disrupt the ordering of retinal axons (Thanos et al., 1984). Both sets of observations strongly suggest that the coursecorrecting axons are responding to positional markers associated with the medial-lateral axis. At the present time, though, in vitro attempts have failed to demonstrate distinctions made by retinal axons between membranes from medial and lateral tectum (Walter et al., 1987a). However, the TOP antigen identified in embryonic chicks (Trisler et al., 1981) is present in a graded distribution along the medial-lateral tectal axis, and in a parallel gradient along the topographically matched ventral-dorsal axis of the retina (Trisler and Collins, 1987). It has been suggested that this molecule may provide a positional signal based on a mechanism of homophilic association between TOP molecules present on the surfaces of retinal axons and tectal cells (Trisler and Collins, 1987).

\section{Comparisons of development of retinotopic order}

As we have shown, in chicks peripheral temporal retinal axons not only make targeting errors within the tectum, but also form arbors at very aberrant and widespread positions. Such behavior does not seem to be unique to late-arriving axons arising from peripheral temporal retina. There is ultrastructural evidence that the first synapses of retinal origin are formed at the rostral border of the tectum by the axons of centrally located ganglion cells which are topographically matched with central tectum (McGraw and McLaughlin, 1980; McLoon, 1985). Further, a proportion of nasal axons destined for caudal tectum form short side branches (Thanos and Bonhoeffer, 1987) and occasional ectopic arbors (Matsui et al., unpublished observations) within rostral tectal regions. However, there seem to be some inconsistencies between our findings and those of Thanos and Bonhoeffer (1987). Although the focus of their study was on the development of individual, DiI-labeled retinal arbors in the chick tectum, they mention that the majority of axons grow directly to their projection areas along straight routes and that it is essential for only a minority $(<5 \%)$ of the axons to correct their position along the medial-lateral axis. We find that about $40 \%$ of temporal axons do so. It is possible that this discrepancy results from regional differences in the frequency of targeting errors. In vitro studies have uncovered some regional distinctions in the behavior of retinal axons, in particular differences between axons arising from nasal and temporal retina (see, for example, Bonhoeffer and Huf, 1985; Walter et al., 1987b).

The evidence suggests that the topographic ordering of retinal projections in mammals is established through a series of events similar to those in the chick. Retrograde labeling studies in rats indicate that a proportion of retinal ganglion cells projects to topographically inappropriate parts of the contralateral (O'Leary et al., 1986) and ipsilateral (Martin et al., 1983) superior colliculus. Further, HRP fills of optic tract axons have revealed that retinocollicular axons (Schneider et al., 1981; Sachs et al., 1986) transiently possess numerous side branches along their length and have provided suggestive evidence for topographic course corrections made by retinal axons within the cat lateral geniculate nucleus (Sretevan and Shatz, 1987). More recently, 
anterograde DiI-labeling studies suggest that the initial topographic targeting of retinal axons in developing rats is even more diffuse than in chicks (Simon and O'Leary, 1989).

However, relating our findings in the chick to those obtained in developing frogs and fish is not as straightforward, making it necessary to discuss the findings in more detail. Holt and Harris (1983) have reported that the Xenopus retinotectal projection is topographically ordered from the beginning of tectal innervation (stages 39-40). Retinotopic order along the mediallateral axis was demonstrated autoradiographically by excising and incubating the ventral or dorsal half of the retina in ${ }^{3} \mathrm{H}-$ proline and replacing it prior to axon outgrowth. Using the same technique, Holt (1984) confirmed that half- or third-eye segments of dorsal or ventral retina project to the topographically correct region of tectum, but with some imprecision. Intercase comparisons suggest that the labeling from dorsal and ventral half-eye segments would overlap by $20-30 \mu \mathrm{m}$ along the mediallateral axis (which measures about $100 \mu \mathrm{m}$ at stages 39-40), whereas the labeling from dorsal and ventral third-eye segments would meet near the middle of the axis. O'Rourke and Fraser (1986) obtained similar results by exchanging half-eye segments labeled with fluorescent dextrans for the equivalent eye segments in unlabeled hosts. The dorsal and ventral half-eye segments preferentially project to the correct region of tectum, but again intercase comparisons suggest that on average the half-eye projections would overlap by about $20-25 \mu \mathrm{m}$ at stage 47 , an amount equivalent to $11-14 \%$ of the medial-lateral tectal axis which measures about $180 \mu \mathrm{m}$ at this age (derived from figure 6 of O'Rourke and Fraser, 1986). These findings suggest that the organization of the early Xenopus retinotectal projection along the medial-lateral tectal axis is less precise than at later stages. Observations made on individually labeled retinal axons in frogs indicate that the source of this imprecision seems to be the formation of large (relative to the size of the tectum), but topographically ordered, retinal arbors. At early larval stages (stages $40-45$ ), the arbors of individual retinal axons cover $33-50 \%$ of the medial-lateral tectal axis; but $94 \%$ of the arbors ( 60 out of 64) labeled from dorsal and ventral retina of frogs between stages 40 and 50 are formed in topographically appropriate positions in the tectum (Sakaguchi and Murphey, 1985).

Using electrophysiological techniques to map visual responses, Holt and Harris (1983) have also found that retinotopic order is present early on along the rostral-caudal tectal axis. However, O'Rourke and Fraser (1986) report that a refined topographic order along this axis emerges gradually. By labeling temporal or nasal hemiretinas with fluorescent dextrans and following the tectal labeling pattern over time in the same tadpoles, they have shown that the projections from central parts of temporal and nasal retina are initially coincident, but later segregate. The segregation is due to a caudal extension of nasal fibers into caudal tectum, with no retraction of temporal fibers which cover a constant relative amount $(48 \%)$ of the rostrocaudal extent of the tectum (which increases slightly in length over this period) immediately before (stage 47) and after (stage 49) segregation. A similar process occurs in zebrafish. Stuermer (1988a) has shown with DiI and DiO labeling of retina that nasal and temporal axons initially overlap within rostral tectum, but nasal axons progress into open caudal tectum; temporal axons are always restricted to the rostral half of tectum. An overlap of nasal and temporal axons within rostral tectum is expected since nasal axons enter the tectum at its rostral edge and thus must grow over its rostral half to reach their appro- priate terminal region (see Stuermer, 1988a, for discussion). But nasal axons reportedly do not transiently extend side branches in rostral tectum in zebrafish (Stuermer, 1988a), nor in Xenopus (Fujisawa, 1987). Thus, in frogs and fish retinotopic order along the rostral-caudal tectal axis is achieved by a selective growth of nasal axons into the appropriate, caudal half of tectum.

These reports indicate that the initial retinotectal projection in lower vertebrates is less precise than at later ages, but that there is accuracy in the topographic targeting of early-arriving retinal axons. However, since the axons that we have studied in chicks arise from more peripheral retina and thus arrive relatively late to the tectum, it may be more appropriate to relate our findings to those of Fujisawa (1987), who labeled individual axons arising from peripheral parts of the retina of stage 50 Xenopus tadpoles. Fujisawa, who analyzed 29 axons that were in the process of approaching the tectum or growing within it and 32 axons that were in early stages of arbor formation, found the targeting and arborization of every axon to be topographically appropriate. Thus, the topographic targeting and arborization of later-arriving, peripheral retinal axons in frogs also seem to be accurate.

It appears, then, that there is a difference between lower vertebrates and chicks in the degree of topographic specificity in the initial targeting of retinotectal axons. However, it is difficult to make strong comparisons since features of their visual systems differ considerably. For instance, at the time the retinotectal projection is being established, the tectum in frogs and fish is extremely small compared with that in chicks (the area of the chick tectum being about $10^{3}$ times greater), yet the early arbors are comparable in size (Sakaguchi and Murphey, 1985; Thanos and Bonhoeffer, 1987; Stuermer, 1988a). Further, the tectum in frogs and fish continues to add neurons to its caudal margin long after retinal axons invade it (Gaze et al., 1974; Raymond and Easter, 1983), whereas in chicks tectal neurogenesis is finished early in the development of the retinotectal projection (LaVail and Cowan, 1971b). Nonetheless, in frogs and fish, as well as in chicks, the early retinotectal projection is less precise than at later stages, but an increase in precision develops by very different means. In frogs (Sakaguchi and Murphey, 1985; Fujisawa, 1987) and fish (Stuermer, 1988a), an increased precision in the map is slowly achieved as the arbors of individual retinal axons come to occupy a smaller percentage of the tectum as the fish matures. Again, this is not due to arbor retraction, but it achieved by a substantial growth of the tectum with a concurrent, but lesser increase in arbor size. In chicks, increased map precision is rapidly brought about by course corrections and the elimination of mistargeted axons, axon segments, and arbors.

Our observations of the developing chick retinotectal projection resemble the events that lead to the reestablishment of topographic order in the regenerating retinotectal projection of lower vertebrates. Regenerating retinal axons in newts (Fujisawa et al., 1982) and fish (Stuermer, 1988b) enter the tectum at incorrect points along its medial-lateral axis, extend exploratory branches, make course corrections, and eliminate topographically inappropriate branches. It is interesting that under conditions of regeneration, many of the distinctions in neurogenesis between higher and lower vertebrates no longer apply: During regeneration a large number of retinal axons grow simultaneously over sizable distances to innervate a large tectum. Whether these observations are causally related or simply coincidental remains open to speculation. 


\section{References}

Auerbach, R., L. Kubai, D. Knighton, and J. Folkman (1974) A simple procedure for the long-term cultivation of chicken embryos. Dev. Biol. 41: 391-394.

Becker, D. L., and J. E. Cook (1987) Initial disorder and secondary retinotopic refinement of regenerating axons in the optic tract of the goldfish: Signs of a new role for axon collateral loss. Development 301: 323-337.

Bonhoeffer, F., and A. Gierer (1984) How do retinal axons find their targets on the tectum? Trends Neurosci. 7: 378-381.

Bonhoeffer, F., and J. Huf (1980) Recognition of cell types by axonal growth cones in vitro. Nature 288: 162-164.

Bonhoeffer, F., and J. Huf (1982) In vitro experiments on axon guidance demonstrating an anterior-posterior gradient on the tectum. EMBO J. $1:$ 427-431.

Bonhoeffer, F., and J. Huf (1985) Position-dependent properties of retinal axons and their growth cones. Nature 315: 409-410.

Bunt, S. M., R. D. Lund, and P. W. Land (1983) Prenatal development of the optic projection in albino and hooded rats. Dev. Brain Res. 6: 149-168.

Cajal, S. Ramon y (1889) Sur la morphologie et les connexions des elements de la retine des oiseaux. Anat. Anz. 4:111-121.

Cajal, S. Ramon y (1911) Histologie du systeme nerveux de l'homme et des vertebres, Vol. 2, Maloine, Paris.

Catsicas, S., M. Catsicas, and P. G. H. Clarke (1987) Long-distance intraretinal connections in birds. Nature 326: 186-187.

Crossland, W. J., and C. J. Uchwat (1979) Topographic projections of the retina and optic tectum upon the ventral lateral geniculate nucleus in the chick. J. Comp. Neurol. 185: 87-106.

Crossland, W. J., W. M. Cowan, and L. A. Rogers (1975) Studies on the development of the chick optic tectum. IV. An autoradiographic study of the development of retino-tectal connections. Brain Res. 91: 1-23.

Easter, S. S., and C. A. O. Stuermer (1984) An evaluation of the hypothesis of shifting terminals in goldfish optic tectum. J. Neurosci. 4: $1052-1063$.

Fraser, S. E. (1980) A differential approach to the patterning of nerve connections. Dev. Biol. 79: 453-464.

Fraser, S. E. (1983) Fiber optic mapping of the Xenopus visual system: Shift in the retinotectal projection during development. Dev. Biol. 95: 505-511.

Fujisawa, H. (1984) Pathways of retinotectal projection in developing Xenopus tadpoles revealed by selective labeling of retinal axons with horseradish peroxidase (HRP). Dev. Growth Differ. 26: 545-553.

Fujisawa, H. (1987) Mode of growth of retinal axons within the tectum of Xenopus tadpoles, and implications in the ordered neuronal connections between the retina and the tectum. J. Comp. Neurol. 260: 127-139.

Fujisawa, H., N. Tani, K. Watanabe, and Y. Ibata (1982) Branching of retinal axons and preferential selection of appropriate branches for specific neuronal connection in the newt. Dev. Biol. 90: 43-57.

Gaze, R. M., M. J. Keating, and S. H. Chung (1974) The evolution of the retinotectal map during development in Xenopus. Proc. R. Soc. London [Biol.] 185: 301-330.

Gierer, A. (1981) Development of projections between areas of the nervous system. Biol. Cybernet. 42: 69-78.

Gierer, A. (1983) Model for the retino-tectal projection. Proc. R. Soc. London [Biol.] 218: 77-93.

Gierer, A. (1987) Directional cues for growing axons forming the retinotectal projection. Development 101: 479-489.

Goldberg, S. (1974) Studies on the mechanics of development of the visual pathways of the chick. Dev. Biol. 36: 24-43.

Goldberg, S., and A. J. Coulombre (1972) Topographical development of the ganglion cell fiber layer in the chick retina. A whole mount study. J. Comp. Neurol. 146: 507-518.

Halfter, W., M. Claviez, and U. Schwarz (1981) Preferential adhesion of tectal membranes to anterior embryonic chick retina neurites. Nature 292: 67-70.

Halfter, W., D. F. Newgreen, J. Sauter, and U. Schwarz (1983) Oriented axon outgrowth from avian embryonic retinae in culturc. Dev. Biol. 95: 56-64.

Hamburger, V., and H. L. Hamilton (1951) A series of normal stages in the development of the chick embryo. J. Morphol. 88: 49-92.

Harris, W. A., C. E. Holt, and F. Bonhoeffer (1987) Retinal axons with and without their somata, growing to and arborizing in the tectum of Xenopus embryos: A time-lapse video study of single fibers in vivo. Development 101: 123-133.

Holt, C. E. (1984) Does timing of axon outgrowth influence initial retinotectal topography in Xenopus? J. Neurosci. 4: 1130-1152.

Holt, C. E., and W. A. Harris (1983) Order in the initial retinotectal map in Xenopus: A new technique for labelling growing nerve fibers. Nature 301: 150-152.

Honig, M. G., and R. I. Hume (1986) Fluorescent carbocyanine dyes allow living neurons of identified origin to be studied in long-term cultures. J. Cell Biol. 103: 171-187.

Hughes, W. F., and S. C. McLoon (1979) Ganglion cell death during normal retinal development in the chick: Comparisons with cell death induced by early target field destruction. Exp. Neurol. 66: 587-601.

Innocenti, G. M. (1981) Growth and reshaping of axons in the establishment of visual callosal connections. Science 212: 824-827.

Insausti, R., C. Blakemore, and W. M. Cowan (1984) Ganglion cell death during development of ipsilateral retinocollicular projection in golden hamster. Nature 308: 362-375.

Kahn, A. J. (1973) Ganglion cell formation in the chick neural retina. Brain Res. 63: 285-290.

Kelly, J. P., and W. M. Cowan (1972) Studies on the development of the chick optic tectum. III. Effects of early eye removal. Brain Res. 158: 207-212.

LaVail, J. H., and W. M. Cowan (1971a) The development of the chick optic tectum. I. Normal morphology and cytoarchitectonic development. Brain Res. 28: 391-419.

LaVail, J. H., and W. M. Cowan (1971b) The development of the chick optic tectum. II. Autoradiographic studies. Brain Res. 28: 421441.

Martin, P. R., A. J. Sefton, and B. Dreher (1983) The retinal location and fate of ganglion cells which project to the ipsilateral superior colliculus in neonatal albino and hooded rats. Neurosci. Lett. 41: 219-226.

McGraw, C. F., and B. J. McLaughlin (1980) Fine structural studies of synaptogenesis in the superficial layers of the chick optic tectum. J. Neurocytol. 9: 79-93.

McLoon, S. C. (1982) Alterations in precision of the crossed retinotectal projection during chick development. Science 215: 1418-1420.

McLoon, S. C. (1985) Evidence for shifting connections during development of the chick retinotectal projection. J. Neurosci. 5: 25702580.

McLoon, S. C., and R. D. Lund (1982) Transient retinofugal pathways in the developing chick. Exp. Brain Res. 45: 277-284.

Nakamura, H., and D. D. M. O'Leary (1988) Development of topographic precision in chick retinotectal projection involves major remodeling. Soc. Neurosci. Abstr. 14: 580.

O'Leary, D. D. M. (1987) Remodeling of early axonal projections through the selective elimination of neurons and long axon collaterals. In Selective Neuronal Death, G. Bock and M. O'Connor, eds., pp. 113-142, Wiley, Chichester, UK.

O'Leary, D. D. M., and T. Terashima (1988) Cortical axons branch to multiple subcortical targets by interstitial axon budding: Implications for target recognition and "waiting periods." Neuron 1:901910.

O'Leary, D. D. M., B. B. Stanfield, and W. M. Cowan (1981) Evidence that the postnatal restriction of the cells of origin of the callosal projection is due to the elimination of axonal collaterals rather than to the death of neurons. Dev. Brain Res. 1: 607-617.

O'Leary, D. D. M., C. R. Gerfen, and W. M. Cowan (1983) The development and restriction of the ipsilateral retinofugal projection in the chick. Dev. Brain Res. 10: 93-109.

O'Leary, D. D. M., J. W. Fawcett, and W. M. Cowan (1986) Topographic targeting errors in the retinocollicular projection and their elimination by selective ganglion cell death. J. Neurosci. 6: 36923705.

O'Rourke, N. A., and S. E. Fraser (1986) Dynamic aspects of retinotectal map formation revealed by a vital-dye fiber-tracing technique. Dev. Biol. 114: 265-276.

Rager, G. H. (1980) Development of the retinotectal projection in the chicken. Adv. Anat. Embryol. Cell Biol. 63: 1-92.

Rager, G., and U. Rager (1978) Systems matching by degeneration I. A quantitative electron microscopic study of the generation and degeneration of ganglion cells in the chicken. Exp. Brain Res. 33: 6578. 
Rager, G., and B. von Oeynhausen (1979) Ingrowth and ramification of retinal fibers in the developing optic tectum of the chick embryo. Exp. Brain Res. 35: 213-227.

Raymond, P. A., and S. S. Easter (1983) Postembryonic growth of the optic tectum in goldfish. J. Neurosci. 3: 1077-1091.

Reh, T. A., and M. Constantine-Paton (1984) Retinal ganglion cell terminals change their projection sites during larval development of Rana pipiens. J. Neurosci. 4: 442-457.

Reperant, J. (1973) Nouvelles données sur les projections visuelles chez le pigeon (Columbia livia). J. Hirnforsch. 14: 151-187.

Sachs, G. M., M. Jacobson, and V. S. Caviness, Jr. (1986) Postnatal changes in arborization pattern of murine retinocollicular axons. $J$. Comp. Neurol. 246: 395-408.

Sakaguchi, D. S., and R. K. Murphey (1985) Map formation in the developing Xenopus retinotectal system: An examination of ganglion cell terminal arborizations. J. Neurosci. 5: 3228-3245.

Schneider, G. E., L. Rava, G. M. Sachs, and S. Jhaveri (1981) Widespread branching of retinotectal axons: Transient in normal development and anomalous in adults with neonatal lesions. Soc. Neurosci. Abstr. 7: 732.

Simon, D. K., and D. D. M. O'Leary (1989) Limited topographic specificity in the targeting and branching of mammalian retinal axons. Dev. Biol. (in press).

Sperry, R. W. (1943a) Effect of $180^{\circ}$ rotation of the retinal field of visuomotor coordination. J. Exp. Zool. 92; 236-279.

Sperry, R. W. (1943b) Visuomotor coordination in the newt (Triturus viridescens) after regeneration of the optic nerve. J. Comp. Neurol. 79: 33-35.

Sperry, R. W. (1963) Chemoaffinity in the orderly growth of nerve fiber patterns and connections. Proc. Natl. Acad. Sci. USA 50: 703710 .

Sretavan, D. W., and C. J. Shatz. (1986) Prenatal development of retinal ganglion cell axons: Segregation into eye-specific layers within the cat's lateral geniculate nucleus. J. Neurosci. 6: 234-251.

Sretevan, D. W., and C. J. Shatz (1987) Axon trajectories and pattern of terminal arborization during the prenatal development of the cat's retinogeniculate pathway. J. Comp. Neurol. 255: 386-400.

Stanfield, B. B., D. D. M. O'Leary, and C. Fricks (1982) Selective collateral elimination in early postnatal development restricts cortical distribution of rat pyramidal tract neurones. Nature 298: 371-373.
Stone, L. S. (1941) Transplantation of the vertebrate eye and return of vision. Trans NY Acad. Sci. 3: 208-212.

Stone, L. S. (1944) Functional polarization in the retinal development and its reestablishment in regenerating retinae of rotated grafted eyes. Proc. Soc. Exp. Biol. Med. 57: 13-14.

Stuermer, C. A. O. (1988a) Retinotopic organization of the developing retinotectal projection in the zebrafish embryo. J. Neurosci. 8: 45134530 .

Stuermer, C. A. O. (1988b) Trajectories of regenerating retinal axons in the goldfish tectum: II. Exploratory branches and growth cones on axons at early regeneration stages. J. Comp. Neurol. 267: 69-91.

Thanos, S., and F. Bonhoeffer (1983) Investigations on development and topographic order of retinotectal axons: Anterograde and retrograde staining of axons and their perikarya with rhodamine in vivo. J. Comp. Neurol. 219: 420-430.

Thanos, S., and F. Bonhoeffer (1984) Development of the transient ipsilateral retinotectal projection in the chick embryo: A numerical fluorescence microscopic analysis. J. Comp. Neurol. 224: 407-414.

Thanos, S., and F. Bonhoeffer (1987) Axonal arborization in the developing chick retinotectal system. J. Comp. Neurol. 261: 155-164.

Thanos, S., F. Bonhoeffer, and U. Rutishauser (1984) Fiber-fiber interaction and tectal cues influence the development of the chick retinotectal projection. Proc. Natl. Acad. Sci. USA 78: 2145-2149.

Trisler, D., and F. Collins (1987) Corresponding spatial gradients of TOP molecules in the developing retina and optic tectum. Science 237: 1208-1209.

Trisler, G. D., M. D. Schneider, and M. Nirenberg (1981) A topographic gradient of molecules in retina can be used to identify neuron position. Proc. Natl. Acad. Sci. USA 78: 2145-2149.

Walter, J., B. Kern-Veits, J. Huf, B. Stolze, and F. Bonhoeffer (1987a) Recognition of position-specific properties of tectal cell membranes by retinal axons in vitro. Development 101: 685-696.

Walter, J., S. Henke-Fahle, and F. Bonhoeffer (1987b) Avoidance of posterior tectal membranes by temporal retinal axons. Development 101: 909-913.

Weysse, A. W., and W. S. Burgess (1906) Histogenesis of the retina. Am. Naturalist 40: 611-637.

Williams, R. W., and P. Rakic (1985) Dispersion of growing axons within the optic nerve of the embryonic monkey. Proc. Natl. Acad. Sci. USA 82 : 3906-3910. 